\title{
Evidence for a non-canonical JAK/STAT signaling pathway in the synthesis of the brain's major ion channels and neurotransmitter receptors
}

\author{
Kathryn M. Hixson ${ }^{1,2}$, Meaghan Cogswell ${ }^{1}$, Amy R. Brooks-Kayal ${ }^{3}$ and Shelley J. Russek ${ }^{1,2,4^{*}}$ [D
}

\begin{abstract}
Background: Brain-derived neurotrophic factor (BDNF) is a major signaling molecule that the brain uses to control a vast network of intracellular cascades fundamental to properties of learning and memory, and cognition. While much is known about BDNF signaling in the healthy nervous system where it controls the mitogen activated protein kinase (MAPK) and cyclic-AMP pathways, less is known about its role in multiple brain disorders where it contributes to the dysregulated neuroplasticity seen in epilepsy and traumatic brain injury (TBI). We previously found that neurons respond to prolonged BDNF exposure (both in vivo (in models of epilepsy and TBI) and in vitro (in BDNF treated primary neuronal cultures)) by activating the Janus Kinase/Signal Transducer and Activator of Transcription (JAK/STAT) signaling pathway. This pathway is best known for its association with inflammatory cytokines in non-neuronal cells.
\end{abstract}

Results: Here, using deep RNA-sequencing of neurons exposed to BDNF in the presence and absence of well characterized JAK/STAT inhibitors, and without non-neuronal cells, we determine the BDNF transcriptome that is specifically regulated by agents that inhibit JAK/STAT signaling. Surprisingly, the BDNF-induced JAK/STAT transcriptome contains ion channels and neurotransmitter receptors coming from all the major classes expressed in the brain, along with key modulators of synaptic plasticity, neurogenesis, and axonal remodeling. Analysis of this dataset has revealed a unique non-canonical mechanism of JAK/STATs in neurons as differential gene expression mediated by STAT3 is not solely dependent upon phosphorylation at residue 705 and may involve a BDNF-induced interaction of STAT3 with Heterochromatin Protein 1 alpha (HP1a).

Conclusions: These findings suggest that the neuronal BDNF-induced JAK/STAT pathway involves more than STAT3 phosphorylation at 705, providing the first evidence for a non-canonical mechanism that may involve HP1a. Our analysis reveals that JAK/STAT signaling regulates many of the genes associated with epilepsy syndromes where BDNF levels are markedly elevated. Uncovering the mechanism of this novel form of BDNF signaling in the brain may provide a new direction for epilepsy therapeutics and open a window into the complex mechanisms of STAT3 transcriptional regulation in neurological disease.

Keywords: JAK/STAT, Neurons, RNAseq, BDNF, HP1a, Epilepsy

\footnotetext{
* Correspondence: srussek@bu.edu

'Laboratory of Translational Epilepsy, Department of Pharmacology \&

Experimental Therapeutics, Boston University School of Medicine (BUSM),

Boston, USA

${ }^{2}$ Graduate Program for Neuroscience (GPN), Boston University (BU), Boston,

USA

Full list of author information is available at the end of the article
}

(c) The Author(s). 2019 Open Access This article is distributed under the terms of the Creative Commons Attribution 4.0 International License (http://creativecommons.org/licenses/by/4.0/), which permits unrestricted use, distribution, and reproduction in any medium, provided you give appropriate credit to the original author(s) and the source, provide a link to the Creative Commons license, and indicate if changes were made. The Creative Commons Public Domain Dedication waiver (http://creativecommons.org/publicdomain/zero/1.0/) applies to the data made available in this article, unless otherwise stated. 


\section{Background}

In the injured brain, it has been suggested that neurogenesis [1], mossy fiber sprouting [2], and hippocampal cell death [3] contribute to aberrant neuronal circuit reorganization. One manifestation of this reorganization is thought to be altered long-term potentiation (LTP)-induced synaptic plasticity [4], which is associated with altered levels of particular neurotransmitter receptors and ion channels $[5,6]$. As the functional properties of neurons change, a state of unchecked overexcitation may occur and is accompanied by decreased GABA-mediated inhibition [7]. Many believe that a major mechanism for this altered brain plasticity is the increased synthesis and release of Brain-derived Neurotrophic Factor (BDNF), a major brain signaling molecule that plays an important role throughout life. BDNF is a neurotrophin ubiquitously expressed in the whole brain with a major role in activity-dependent alterations in neuronal morphology and synaptogenesis. Protein and mRNA levels of BDNF are markedly increased after seizures in brain regions involved in epileptogenesis $[8,9]$ and mutations in $B D N F$ can reduce the development of spontaneous seizures in animal models [10]. Moreover, a conditional deletion of the high-affinity BDNF receptor TrkB in a subset of neurons, is sufficient to completely eliminate all behavioral evidence of the progression of epilepsy in the kindling model [11] and it has been shown that enhanced TrkB signaling can exacerbate epileptogenesis [12].

In addition to the TrkB-mediated BDNF response, the p75 Neurotrophin Receptor (p75NTR, also referred to as NGFR) is a low-affinity receptor for the cleaved mature form of BDNF while a high-affinity receptor for the uncleaved form, proBDNF. p75NTR levels are elevated after Status Epilepticus (SE) in animals and increased activation by proBDNF, like mature BDNF, increases susceptibility to seizures [13, 14]. Interestingly, our labs have shown that increased synthesis of proBDNF, and not mature BDNF, is the first response of the injured brain in the pilocarpine (PILO) model of epilepsy prior to SE-induced increases of p75NTR [15]. This finding suggests that high levels of proBDNF may exert their effects through TrkB rather than p75NTR.

In the normal brain, BDNF activation of its receptors regulates multiple signaling pathways: mitogenactivated protein kinase/extracellular signal-regulated protein kinase (MAPK/ERK), phospholipase $\mathrm{C \gamma}$ (PLC $\gamma$ ), phosphoinositide 3-kinase (PI3K), c-Jun Nterminal kinase (JNK), and NFkB [16]. It is well established that BDNF modulates long-term potentiation (LTP) at Schaffer collateral-CA1 and mossy fiber-CA3 hippocampal synapses by acting through TrkB [17-21]. Although p75NTR is not implicated in LTP, it plays a significant role in learning and memory through its modulation of hippocampal long-term depression (LTD) by altering AMPA receptor expression [22].

Studies from our laboratories demonstrate that in addition to the signaling pathways described above, increased levels of BDNF activate the Janus kinase/signal transducer and activator of transcription (JAK/STAT) pathway both in vivo, in the rat PILO model of epilepsy, and in vitro, in BDNF-treated primary cultured neurons [23]. The JAK/STAT pathway is a signaling cascade that has a prominent role in immune function and cancer development. The canonical pathway involves the binding of JAK to its target (such as a cytokine or hormone receptor), subsequent JAK phosphorylation that stimulates the recruitment and activation of STAT proteins (phospho-STAT (p-STAT)) and their movement as dimers into the nucleus where they function as transcriptional activators. Although JAK/STATs regulate transcription through this canonical pathway, more recently, non-canonical JAK/STAT signaling has been discovered where JAKs can act independently of STATs to regulate transcription in the nucleus, and STATs can function independently of their phosphorylation state to maintain genome stability via interactions with heterochromatin protein 1 (HP1) [24]. Increasing evidence also suggests that HP1 may be present at euchromatin as well as heterochromatin and involved in gene transcription [25, 26]. While the role, and mechanism, of JAK/STAT signaling in the brain is still not completely understood, it is clear that it is an important part of how the brain regulates its synaptic connections [27].

Research from our laboratory has demonstrated that activation of the JAK/STAT pathway results in the expression of the inducible cAMP early repressor (ICER) via STAT3-mediated gene regulation. Moreover, we show that ICER represses the gene (Gabra1/GABRA1) coding for the $\alpha 1$ subunit of the type A $\gamma$-aminobutyric acid (GABA) receptor (GABAR), the major inhibitory neurotransmitter receptor in the brain, and that such repression reduces the number of $\alpha 1$ containing GABARs in neurons [28]. Most importantly, reduced $\alpha 1$ subunit gene expression also occurs in epilepsy patients [5] as well as in other disorders of the nervous system [29-31]. In addition, use of the JAK/STAT inhibitor, WP1066, in the PILO rat model of epilepsy reduces the number of spontaneous seizures after the latent period [32]. We now hypothesize that in addition to controlling the gene regulation of Gabra1/GABRA1, the BDNF-induced JAK/ STAT pathway controls the expression of diverse gene products that are involved in synaptic plasticity as well as in the epileptogenic process that follows brain injury. We also hypothesize that attenuating this pathway may provide a gateway to new treatments for refractory epilepsy and other brain disorders that display dysregulated neuroplasticity. 
To test these hypotheses, and to gain a comprehensive understanding of the genome impacted by BDNFinduced JAK/STAT activation, we exposed primary cultured neurons to BDNF with and without JAK/STAT inhibitors and performed deep RNA-sequencing (RNAseq) in order to determine the gene set within the BDNF response that could be ascribed to JAK/STAT activation (as defined by WP1066 and Ruxolitinib (Ruxo), a potent inhibitor of JAK1/2 activation [33]). We now report evidence that suggests BDNF acts through the JAK/STAT pathway to execute changes in: the expression of ion channels, neurotransmitter and GPCR receptors, and the expression of key modulators of synaptic plasticity, neurogenesis, and axonal remodeling. Many of these functions were previously ascribed to BDNF, however, the role of the JAK/STAT pathway in their manifestation has never been previously explored. Our studies also reveal the presence of many new BDNF target genes providing a broader landscape for BDNF mediated gene regulation of the healthy and impaired nervous system.

\section{Results}

BDNF signaling and the identification of epilepsyassociated gene networks

Primary cultured neurons were treated with BDNF (0.7 $\mathrm{nM}$, a physiologically relevant level) or vehicle control (water) to determine the genome response to prolonged receptor activation (4h) (Fig. 1). Using RNA-sequencing for open discovery, we identified a total of 2869 differentially expressed genes (DEGs) whose levels change (increase or decrease) in response to BDNF signaling (Fig. 2a) (CTRL vs V + B gene list, Additional file 5). Inspection of the gene set using Ingenuity Pathway Analysis (IPA) [34] revealed that only 83 of these genes have been previously associated with BDNF (as determined using the Ingenuity Knowledge Base, a curated database of all historical scientific information in IPA databases), suggesting that the majority of genes identified in this study are novel in their association with the BDNF signaling pathway. A subset of 194 potential BDNF regulated genes are associated with "seizure disorders" (BDNF and epilepsy, Additional file 5), an umbrella
A

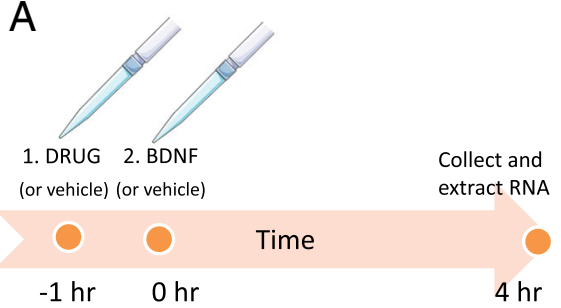

C

V+B vs. CTRL Determines:

ALL BDNF EFFECTS

ON GENE EXPRESSION

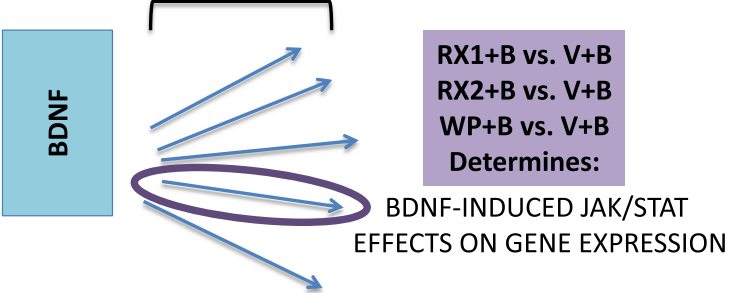

$\mathrm{B}$
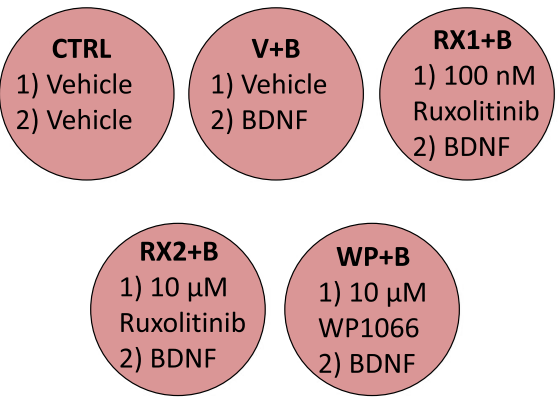

Fig. 1 Schematic of experimental design and analysis. a Timeline representation of the drug treatment protocol, including the $1 \mathrm{~h}$ drug or DMSO (vehicle, V) pretreatment (initiated at $-1 \mathrm{~h}$ ), administration of aqueous BDNF (B) or water (vehicle) treatment (Time $=0 \mathrm{~h}$ ) and time of cell collection and RNA extraction ( $4 \mathrm{~h}$ ). $\mathbf{b}$ 6-well plate showing each one of the 5 treatment groups and the abbreviations by which they will be referred to in the text: DMSO+Water (CTRL), DMSO+BDNF $(V+B), 100$ nM Ruxolitinib+BDNF (RX1 + B), $10 \mu M$ Ruxolitinib+BDNF (RX2 + B), $10 \mu M$ WP1066 + BDNF (WP + B). c Diagram represents the approach taken to identify differential gene expression (DEG) in response to JAK/STAT pathway inhibition. BDNF through its receptors activates multiple signaling pathways (represented by blue arrows) that impact transcription. Differential expression analysis comparing $V+B$ vs. CTRL treatment groups (green box) will reveal the total set of genes that are regulated by BDNF-induced intracellular signaling pathways. To identify BDNF DEGs that are specific to JAK/STAT signaling, comparisons are made between the groups pretreated with JAK inhibitors $(R X 1+B, R X 2+B, W P+B)$ and the group pretreated with vehicle $(V+B)(p u r p l e ~ b o x)$; $D E G s$ from this comparison (where JAKJSTAT inhibition reverses BDNF stimulation or inhibition) are thought to be associated with the JAK/STAT pathway 


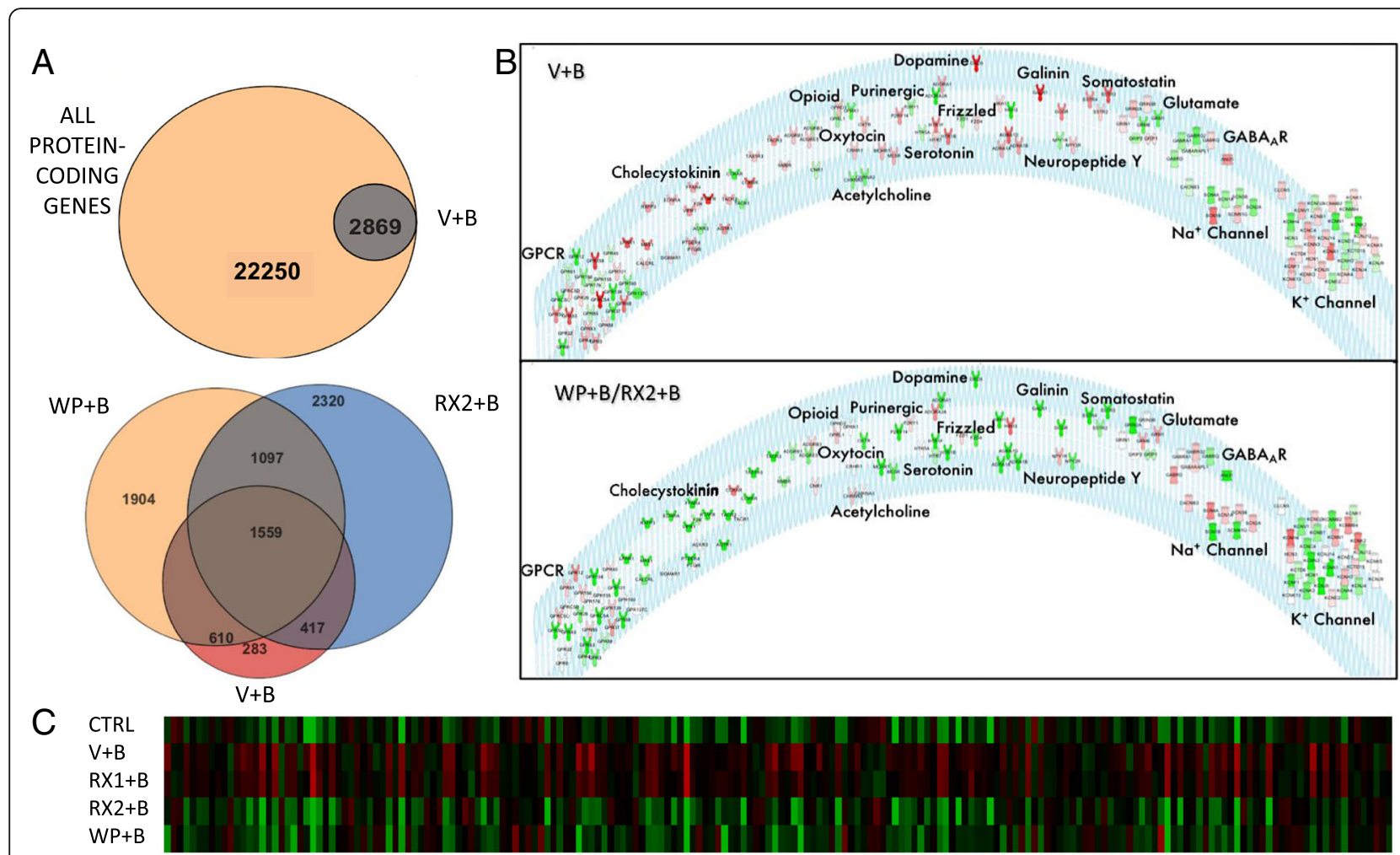

Fig. 2 JAKSSTAT inhibitors reverse BDNF-induced gene expression. a TOP: Venn diagram representation of all protein-coding genes in the rat genome (in accordance with Strand NGS notation) with all differentially expressed genes (DEGs) between primary neurons treated with DMSO+BDNF vs. DMSO+Water. BOTTOM: Venn diagram representation of all DEGs in DMSO+Water vs. DMSO+BDNF (BDNF, Red, 2869), WP1066 + BDNF vs. DMSO+BDNF (WP1066,Orange, 5170 total) and $10 \mu$ M Ruxo+BDNF vs. DMSO+BDNF (RX2, Blue, 5393 total genes). b Receptor and Ion Channel expression is altered by BDNF and rescued by JAK inhibition. TOP: List of Ion Channels and Receptor Subunits whose expression is altered by 4-h BDNF treatment. Color represents direction and degree of fold change (Red: up, Green: down) sorted by receptor or channel type. BOTTOM: Receptor and Ion Channel reversal in expression by addition of WP or RX2 (white receptors are not affected by JAKISTAT inhibitors). Response to BDNF in presence of WP was used as the basis for coloring receptors depicted in the diagram. Red: Upregulated, Green: Downregulated. c Heatmap of all DEGs (columns) associated with Epilepsy (IPA) that are affected by exposure to BDNF. DW: DMSO+Water, DB: DMSO+BDNF, RX1: 100 nM Ruxo+BDNF, RX2:10 $\mu$ M Ruxo+BDNF, WP: $10 \mu M$ WP1066 + BDNF. Green: low expression, red: high expression

category in IPA that includes all epilepsy classes as represented in the curated knowledge base. Moreover, seizure disorder is the primary most significant neurological disorder identified by enrichment analysis of the gene pool $(p=3.29 \mathrm{E}-27)$.

In addition to the 194 epilepsy-associated genes, pathway analysis suggests that increased levels of BDNF alters the expression of essential neurobiological gene sets that are required for brain development and that are dysregulated during epileptogenesis in animal models and human patients. For instance, the differentially expressed set of transcripts from BDNF-treated primary neurons is highly enriched for genes essential to axonal guidance ( $p=1.09 \mathrm{E}-11$ ); further, there is a striking enrichment that is specific to all major classes of ion channels and neurotransmitter/neuropeptide receptors, with 133 of 599 total genes related to one of these categories regulated by prolonged BDNF exposure $(4 \mathrm{~h})(p=2.66 \mathrm{E}$ 11) (Fig. 2b). Specifically, the differentially expressed transcripts for receptors include those activated by GABA, glutamate, acetylcholine, dopamine, opioids, serotonin, galanin, and neuropeptide $\mathrm{Y}$, covering both metabotropic and ionotropic receptor subtypes. Most classes of ion channel genes are also represented, including those for potassium, sodium, and calcium, where mutations have been shown to underlie specific genetic epilepsies [35-37]. There is also a specific decrease (1.73 fold) in the expression of Gabra1 that is a member of the GABAR gene cluster which we have previously demonstrated to be regulated by BDNF using qRT-PCR in extracts of BDNF-treated primary neurons and hippocampal tissue extracted from the in vivo PILO model of temporal lobe epilepsy [23]. As expected, the neuronal RNA-seq dataset revealed that prolonged exposure to BDNF increases BDNF transcript levels, a finding that is well established in the literature [38]. Given our previous identification of a novel JAK/STAT pathway in neurons that is regulated by BDNF, we asked whether any 
members of the JAK/STAT pathway might be regulated at a transcriptional level in response to BDNF receptor activation. Our dataset indicates significant enrichment for transcripts linked to JAK/STAT signaling $(p=6.03 \mathrm{E}-$ 5 ) and in particular, an enrichment of Jak1 (1.6-fold enrichment) and Jak2 (1.8-fold enrichment).

\section{Neuropharmacological dissection of BDNF-induced JAK/ STAT signaling reveals a non-canonical pathway in neurons}

Primary cultured neurons were pre-treated with agents known to inhibit the JAK/STAT pathway (Fig. 1) by interfering with JAK kinase activity, either directly by inhibiting JAK phosphorylation or stimulating JAK degradation. Two different antagonists were employed in these studies: the small molecule WP1066 that has been shown to inhibit JAK2/STAT3 signaling and degrade total JAK2 [39] and Ruxolitinib (Ruxo), currently in use as a cancer therapeutic, which acts on JAK1 and JAK2 by forming two hydrogen bonds with the hinge region of the JAK protein (the segment that connects the N-lobe to the C-lobe of the kinase domain) and reduces phosphorylation of the JAK2 protein at Tyr1007/1008 [33]. Based on our earlier discovery that siRNA knockdown of STAT3 reverses BDNF-induced downregulation in the levels of Gabra1 subunit mRNAs [23], as does WP1066, we used RNA-seq to identify the full set of genes responsive to JAK inhibition. This strategy enables us to unmask those genes in the BDNF transcriptome that may be JAK/STAT dependent.

Comparing the transcriptomes $\operatorname{BDNF}(\mathrm{V}+\mathrm{B})$ or 100 $\mathrm{nM}$ Ruxo + BDNF (RX1 + B), we were surprised to find that there was no difference between these two transcriptomes, as statistically assessed using DSEQ2 (0 DEGs) (FDR $=0.05$, Wald test). To make sure that Ruxo treatment at $100 \mathrm{nM}$ was active in the primary cultures of our studies, Western blot was performed using the same drug stock as used in cultures that generated the RNA-seq libraries. In this control experiment, Ruxo $(100 \mathrm{nM})$ potently inhibited STAT3 phosphorylation at
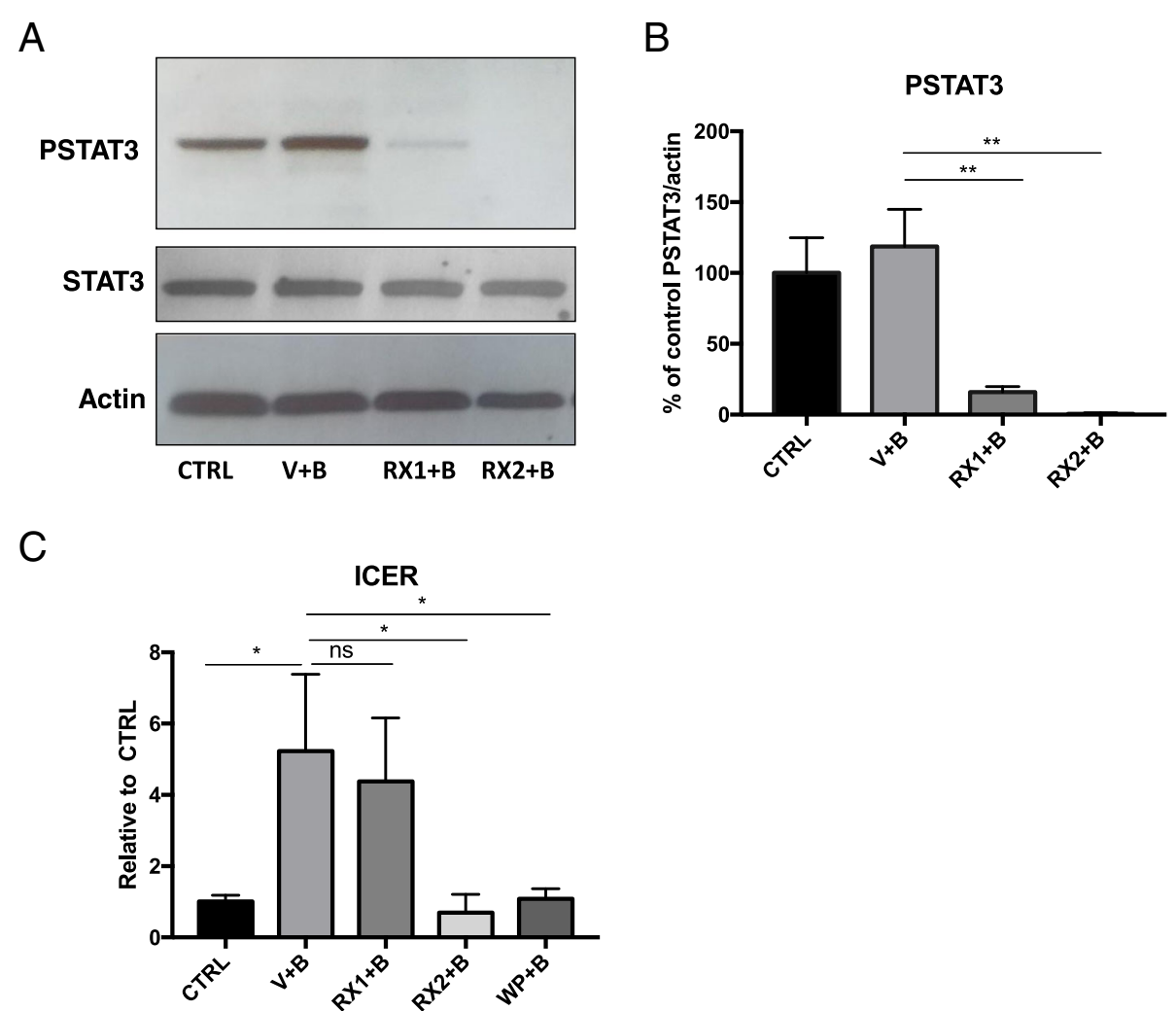

Fig. 3 RX1 and RX2 reduce levels of phospho-STAT3 but only RX2 blocks ICER induction. a Representative Western Blot analysis of whole-cell protein extracts from primary neurons 9 DIV pretreated with100nM Ruxolitinib (RX1), 10uM Ruxo (RX2), or DMSO for $1 \mathrm{~h}$ before the addition of BDNF. Cells were collected $30 \mathrm{~min}$ after BDNF administration and probed with anti pSTAT3, STAT3 and $\beta$-Actin. b Quantitation of signals from densitometry is displayed as mean percent change $\left( \pm\right.$ SEM) relative to the DMSO+Water control group $\left({ }^{* *} p<0.01\right)$. Ruxolitinib significantly reduces the levels of P-STAT3 with no change in total STAT3. c Graphical representation of results from real-time PCR analysis using specific Taqman probe and primers. RNA was extracted from cells collected $4 \mathrm{~h}$ after BDNF administration. Transcript levels are shown as the mean values $( \pm$ SEM) of the ratio relative to the DMSO+Water control group for Icer $n=6$. Note, that while RX1 blocks pSTAT3, it does not block the effect of BDNF treatment on ICER induction, while WP and RX2 do 
30 min $(80 \%+-3.07$ reduction of BDNF signal $)$ and at $4 \mathrm{~h}$ (73\% reduction of BDNF signal, Fig. 3). Therefore, despite reducing STAT3 phosphorylation at Tyr 705, our data taken together demonstrate that $100 \mathrm{nM}$ Ruxo does not alter BDNF-induced gene regulation, including changes in ICER expression (Fig. 3c). This finding suggests that the BDNF-induced JAK/STAT pathway is not STAT3 phosphorylation-dependent even though knockdown of STAT3 with siRNAs prevents ICER induction and Gabra1 downregulation [23]. Note that in our current studies BDNF does not significantly increase STAT3 phosphorylation but Ruxo still inhibits the basal state of its activation. These observations favor the hypothesis that neurons use a non-canonical mechanism of JAK/STAT signaling which may be relevant to epilepsy, and potentially to learning and memory where BDNF is a critical signaling molecule, but require further experimentation.

\section{Using pharmacology to reduce the dimensionality of the dataset and identify potential BDNF-induced JAK/STAT target genes}

While we discovered that co-treatment of neurons with BDNF $(\mathrm{V}+\mathrm{B})$ vs. RX1 + B produced similar transcriptomes, we found that a marked increase in the concentration of Ruxo $(10 \mu \mathrm{M})$ plus BDNF $(\mathrm{RX} 2+\mathrm{B})$ attenuated the expression of multiple genes that were altered in response to BDNF, and most importantly, those that we previously identified in the PILO model of epilepsy. We next compared the RX2 DEG as determined by DESEQ2 $(F D R=0.05$, Wald test) to those generated from cultures treated with $10 \mu \mathrm{M}$ WP1066 plus BDNF $(\mathrm{WP}+\mathrm{B})$ and generated a subset of genes whose BDNFinduced expression was reversed back to vehicle control by both drug treatments. Using these JAK/STAT inhibitors as probes for unmasking potential genes that are regulated by the BDNF-induced JAK/STAT pathway, we identified 1559 of the 2659 BDNF target genes that may be most associated with JAK/STAT signaling in neurons. Interrogation of IPA networks specific to this shared gene set revealed that 131 genes are epilepsy-related and seizure disorder is still the top most significant neurological disease $(P=7.31 \mathrm{E}-22)$. Considering that 131 of the 194 BDNF-regulated epilepsy-linked genes are reversed by JAK/STAT inhibitors (68\%), it suggests that JAK/STAT signaling may be a large component of BDNF-related epileptogenesis. This can be best appreciated by looking at the heat map displayed in Fig. 2c which depicts the expression levels of all 194 epilepsylinked genes that are changed by BDNF treatment. The results clearly show that $\mathrm{WP}+\mathrm{B}(10 \mu \mathrm{M})$ and Ruxo $(\mathrm{RX} 2+\mathrm{B}, 10 \mu \mathrm{M})$ block BDNF-induced changes in neuronal gene expression for epilepsy-linked genes and both appear to have a similar gene expression signature to that of DMSO+Water control. Note that Ruxo at its lower concentration ( $\mathrm{RX} 1+\mathrm{B}, 100 \mathrm{nM})$ looks similar to BDNF alone.

\section{Gene ontology and pathway analysis}

Gene Ontology (GO) term analysis of the WP + B/RX2 + B dataset, performed using EnrichR [40, 41], reveals that the 1559 overlapping genes are significantly associated with molecular functions related to receptor and channel activity (found in 8/10 top molecular functions) (Fig. 4a, top panel). All of the top 10 biological process GO terms include the words "synaptic transmission" (Fig. 4a, middle panel). These consistent findings strongly suggest that both WP and Ruxo have the capacity to regulate synaptic transmission at the gene expression level in the brain. When compared with the total list of receptor/ion channel related genes that were regulated by BDNF (as depicted in Fig. 2b, top panel), 107/133 genes (80\%) were reversed by treatment with JAK/STAT inhibitors (Fig. 2b, bottom panel). This is best seen by the color reversal in the receptors for all but a few that were not significantly affected by pre-treatment with the inhibitor prior to BDNF activation (displayed in white).

In addition, neurotransmitter receptors, axonal guidance, GPCR and c-AMP signaling were found to be amongst the top KEGG pathways associated with the shared gene set of WP + B and RX $2+B$ (Fig. 4a, bottom panel). Members of the JAK/STAT signaling pathway were also identified as significant gene targets $(P=$ $1.044 \mathrm{E}-3)$ suggesting that BDNF may also participate in the feedback regulation of the pathway. Figure $4 \mathrm{~b}$ is a schematic representation showing many of the component molecules that make up the JAK/STAT pathway, with expression of all the colored genes being affected by BDNF treatments and all the ones with a purple border reversed by JAK/STAT inhibitor treatments $\mathrm{WP}+\mathrm{B}$ and $\mathrm{RX} 2+\mathrm{B}$.

In addition to the significant relationship to epilepsy identified by IPA (see Additional file 1: Table S1), the overlapping WP/RX2 gene set had a significant link to neuroinflammation despite the neuronal cultures being largely devoid of any glial cells, 41 genes of the BDNFinduced set of 56 neuroinflammation-linked genes were reversed by $\mathrm{WP}+\mathrm{B}$ or $\mathrm{RX} 2+\mathrm{B}$ treatment $(73 \%$ of the gene set) (Fig. 4c).

\section{Functional relationships between genes as described in the literature}

Pathway and GO analysis identified the following epileptogenic processes, in addition to inflammation, as being enriched in the $\mathrm{WP}+\mathrm{B} / \mathrm{RX} 2+\mathrm{B}$ overlapping data set: synaptic plasticity, receptors and ion channels, epilepsy, transcription factors, proliferation, and neurogenesis. In order to visualize the functional connectivity of 


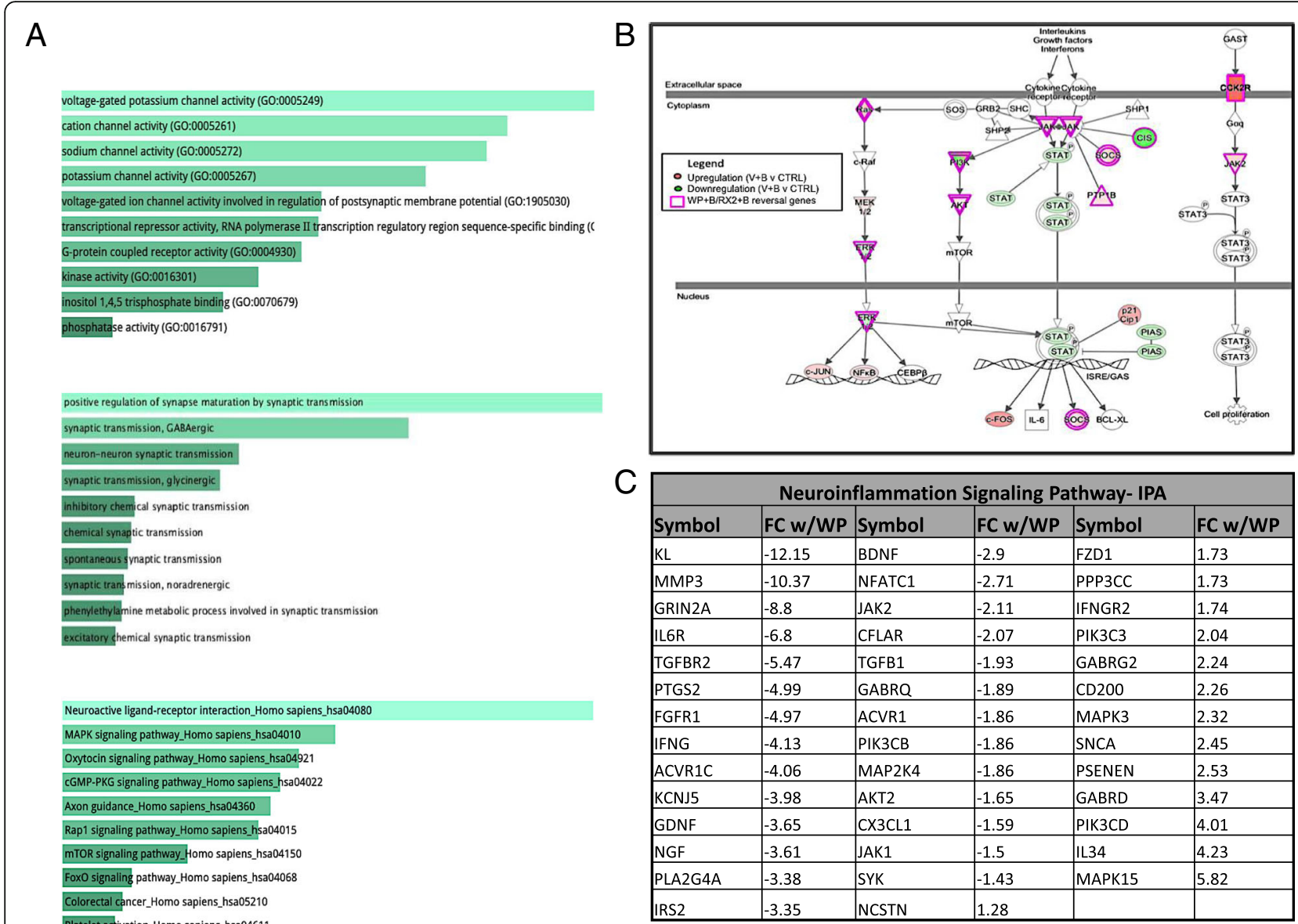

Fig. 4 Pathway Enrichment and Gene Ontology analysis of the overlapping RX2/WP dataset. a Pathways and functions enriched in the list of 1559 genes altered by WP and $10 \mu \mathrm{M}$ Ruxo (RX2). Gene Ontology and KEGG enrichment analysis performed using EnrichR. b Genes involved in the canonical JAK/STAT signaling pathway with functional representation. Genes are colored by degree of fold change 9 with BDNF alone (see panel legend). Purple border signifies that WP $+B$ and RX2 $+B$ reverse effects of BDNF on gene expression. $\mathbf{c}$ List of DEGs involved in neuroinflammatory signaling and degree of fold change of WP $+B$ v $V+B$. Listed in order of FC most negative to most positive

the genes involved in epileptogenesis, we created a functional network of the most significant genes as determined by a $\mathrm{p}$-value of $<1 \times 10^{\wedge} 10$ and a fold-change $>2$ (Additional file 3: Figure S1). Genes that met these conditions were separated into the lists of the epileptogenic processes, as described above. In order to relate these genes to one another and their epileptogenic functions, we created a network that portrays their function, expression fold change, direction, and functional protein relationships in Cytoscape [42](Fig. 5a). Using GENEMania, a Cytoscape tool containing a database of experimental data showing protein-protein interactions [43], we determined potential functional relationships. Each node in the network represents a gene while the edges represents a protein interaction. Node color is determined by the epileptogenic category. Due to the interplay between these functions, many genes within one category overlap with another category. For instance, Egr3 plays a role in 5 of the 6 categories: synaptic plasticity, epilepsy, transcription factors, proliferation, and neurogenesis. The color in this case is determined by whichever category comes first in this list: synaptic plasticity, receptors and ion channels, epilepsy, transcription factors, proliferation, and neurogenesis, where the order is determined by the number of genes in that category from smallest to largest. This was done to avoid having the majority of the nodes colored for the largest category (neurogenesis). For Egr3, it is yellow representing synaptic plasticity, however, its location in the network is near the center because the proximity of the node to other categories represents its link to those secondary categories. In addition, the Venn diagram in $5 \mathrm{~B}$ also shows the degree of overlap for each category. For instance, there are 108 total genes related to receptors and ion channels. In the list, 61 of those did not belong to any other category, 11 were also linked to neurogenesis, 5 to receptors, neurogenesis and proliferation, 14 to receptors and epilepsy, 6 to receptors, epilepsy and 

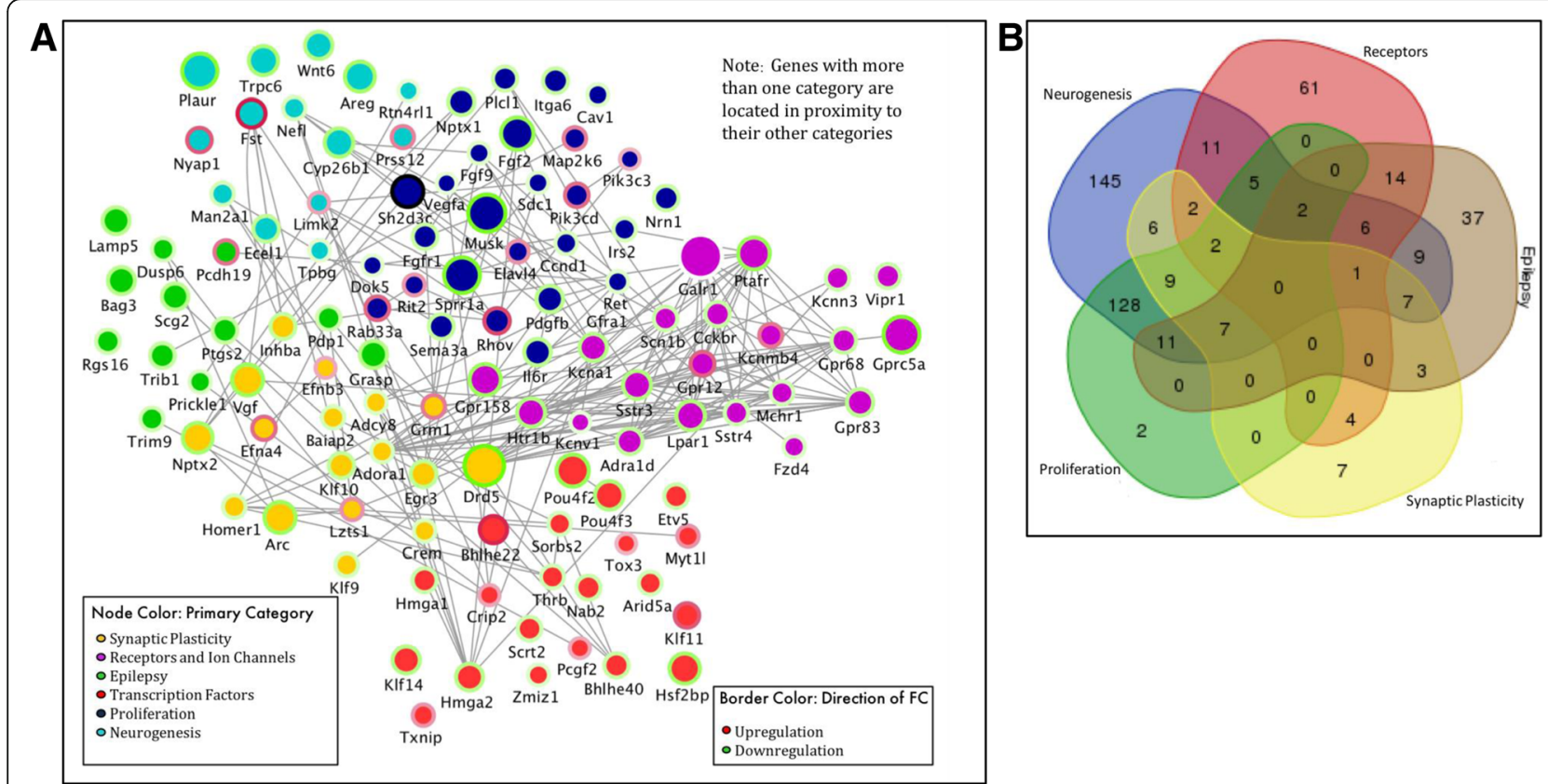

Fig. 5 Functional Network of DEGs involved in epileptogenic-related processes. a Node color represents primary category, determined by order indicated in panel legend. Node size indicates degree of fold change (FC). Border color indicates direction of FC. Gray lines show functional connectivity determined by GeneMania in Cytoscape. Location in network roughly determined by category and multiple associations with neighboring and other categories. (Genes located near the center are involved in multiple categories). $\mathbf{b}$ Venn diagram of genes contained in network diagram in A demonstrating overlap of the genes in each category, neurogenesis (blue), receptors (red), epilepsy (gray), synaptic plasticity (yellow), and proliferation (green). Gene associations provided by IPA

neurogenesis, and 2 to receptors, neurogenesis, epilepsy and proliferation.

\section{Differentially expressed genes exclusive to BDNF/RX2 contain a rich set of epilepsy-associated targets not present in the WP1066 exclusive list}

To further dissect the regulatory contribution of the two JAK/STAT inhibitors, we examined the list of DEGs (as determined by DESEQ2, FDR $=0.05$, Wald test) that differed between $\mathrm{WP}+\mathrm{B}$ and $\mathrm{RX} 2+\mathrm{B}$ treatments. Four hundred seventeen DEGs are reversed by $\mathrm{RX} 2+\mathrm{B}$ treatment that are absent with $\mathrm{WP}+\mathrm{B}$ and 610 DEGs are reversed by WP $+B$ that are not by RX2 + B (Fig. 2a, bottom panel). Interestingly, the genes whose expression is exclusively reversed by $\mathrm{RX} 2+\mathrm{B}$ are significantly related to neurodegeneration, and brain-related movement disorders (i.e., Huntington's disease) as well as to epilepsy. On the other hand, those exclusively regulated by WP $+\mathrm{B}$ were not highly associated with epilepsy or other brain disorders. Additional file 4: Figure S2 contains the EnrichR generated KEGG pathway analysis for this gene set (Additional file 4: Figure S2A). Nine of the 10 top related canonical pathways differ from the KEGG list of overlapping WP/RX2 DEGs (Fig. 4b). Top genes involved in the KEGG pathways listed are also shown in a clustergram (Additional file 4: Figure S2B). The list of genes exclusively regulated by $\mathrm{RX} 2$ + B that are linked to epilepsy, Huntington's disease, and neurodegeneration (E) are also presented (Additional file 4: Figure S2C-E).

\section{qRT-PCR gene validation of datasets}

Many of the genes identified in these RNA-seq studies were originally reported by us in the literature (ICER, Gabra1, Egr3), using a variety of molecular approaches $[23,32,44]$. To further validate the new datasets, we generated an additional set of cultures, originating from the embryos of multiple pregnant rats, and chose the following genes for qRT-PCR because of their interest in the field of epilepsy: Dopamine Receptor D5 (Drd5), Galinin Receptor 1 (Galr1), $\gamma 2$ subunit of the GABAR (Gabrg2), Glutamate metabotropic receptor 1 (Grm1), and their relationship to the JAK/STAT pathway: Inducible cAMP early repressor (Icer), myeloid leukemia cell differentiation protein (Mcl1), Suppressor Of Cytokine Signaling 3 (Socs3), Cyclin D1 (Ccnd1), and C-X-C Motif Chemokine Receptor 4 (Cxcr4) (Fig. 6). In most cases, findings from qRT-PCR were consistent with those of RNA-seq. Quantitated results from select validations are shown (Fig. 6a-d). A results table for all candidates where validation was performed is included in Fig. 6e. All significance was determined using One-Way ANOVA followed by Tukey's test for multiple comparisons. 


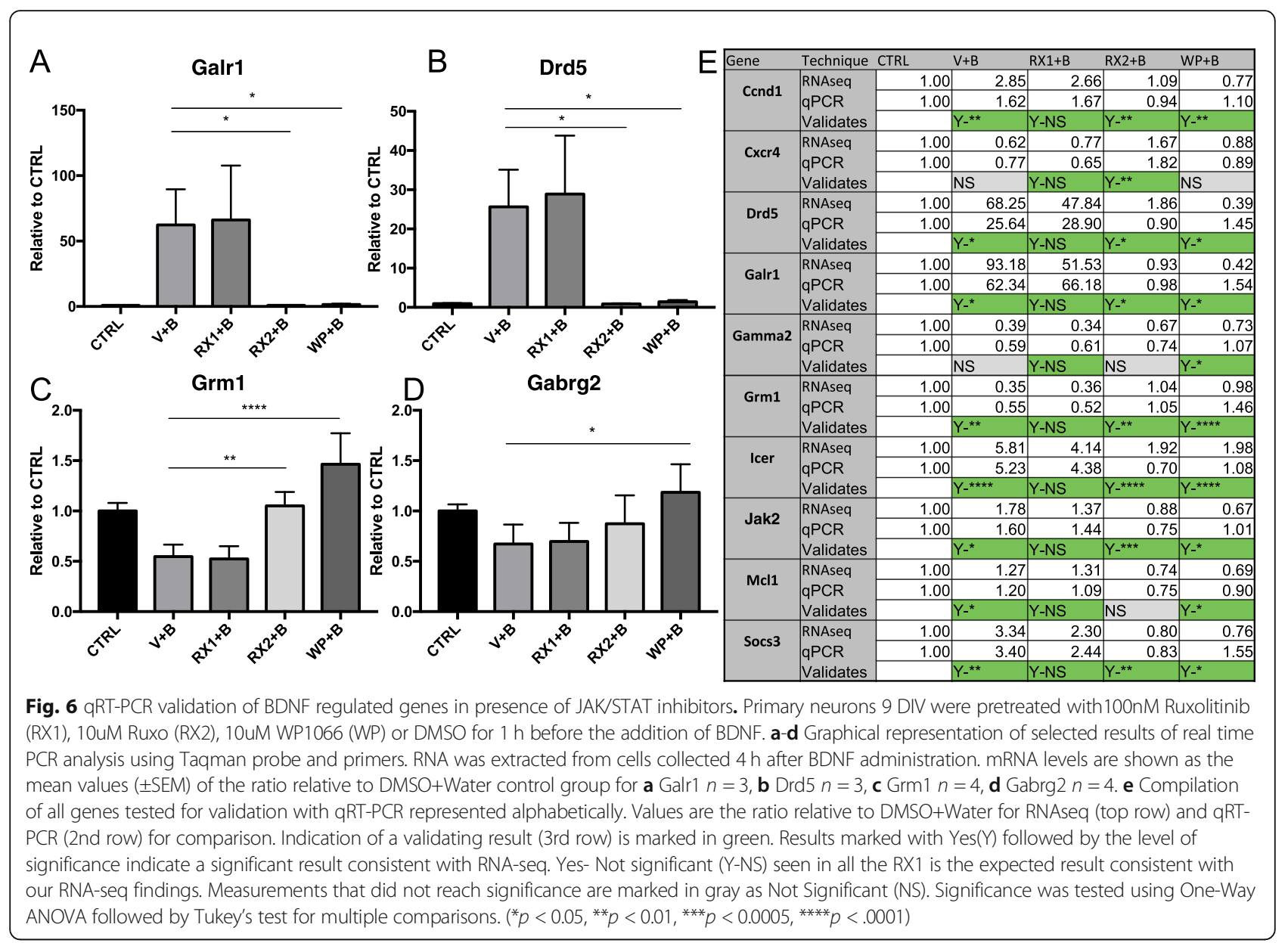

\section{Comparison of DEGs with previously published ChIP-seq datasets}

Using a published set of validated STAT3 targets from chromatin immunoprecipitation (ChIP)-sequencing (ChIPseq) assays, performed with glioblastoma cells [45], we generated a list of 308 genes that were also present in our $\mathrm{WP}+\mathrm{B} / \mathrm{RX} 2+\mathrm{B}$ datasets (Fig. 7). Of particular interest are $B D N F$, Calcium Voltage-Gated Channel Auxiliary Subunit Beta 4 (Cacnb4), Gabrg2, Grm1, Jak1/2, and Sodium Voltage-Gated Channel Alpha Subunit 1(Scn1a). These genes have all been associated with epilepsy models and with human mutations in epilepsy patients [35, 46-48].

\section{HP1a association with STAT3 in neurons}

As a first step to uncover the non-canonical mechanism underlying BDNF-induced JAK/STAT signaling in neurons, we asked whether BDNF treatment alters the association of STAT3 with Heterochromatin Protein 1 Alpha $(\mathrm{HP} 1 \alpha)$, a mediator of gene silencing that is found in heterochromatin. An association of STAT3 with HP1 $\alpha$ has been previously reported in the literature [49] and we expected to find that BDNF might decrease association thereby releasing the DNA for the subsequent binding of transcription factors and transcriptional elongation. To our surprise, however, BDNF increased association of the two proteins which was blocked by the JAK/STAT inhibitors WP and RX2 (Fig. 8).

\section{Discussion}

There is a strong body of evidence suggesting that BDNF signaling through its $\operatorname{TrkB}$ receptor contributes in a major way to the development of TLE, as suggested by animal models of epilepsy [11,50] and their potential relationship to human epilepsy brain pathology [51]. BDNF plays a critical role in the cell biological processes that regulate the structural plasticity of dentate granule cells and the enhanced excitation associated with changes in LTP and compromised GABA-mediated inhibition [17, 46, 50,52]. Although the role BDNF plays in brain disorders is better understood now than at the time of its discovery, many key aspects of its complex regulatory programs remain a mystery. We designed our study to gather a comprehensive list of genes whose expression is either upregulated or downregulated by 


\begin{tabular}{|c|c|c|c|c|c|c|c|c|c|c|c|}
\hline \multirow{2}{*}{ A } & \multirow[b]{2}{*}{ BBX } & \multicolumn{9}{|c|}{ STAT3 ChIP seq Targets } & \multirow[b]{2}{*}{ TXNRD1 } \\
\hline & & CPNE4 & EML1 & GPRC5A & KCNE2 & MAN2A1 & NTRK3 & PRKCQ & RYBP & ST18 & \\
\hline ACTN1 & BCAS3 & CPNE8 & EMP1 & GRIP1 & KCNK2 & MAP2K5 & NVL & PSME4 & SAMD4A & ST6GAL1 & UBASH3B \\
\hline ACTR3B & BDNF & CREBL2 & EPB41L4B & B GRM1 & KCNMB2 & MAP2K6 & OGDHL & PSTPIP2 & SAMHD1 & $\mathrm{SV} 2 \mathrm{C}$ & ULK2 \\
\hline ACVR1C & BHLHE40 & CRHBP & ETV5 & GSPT2 & KCTD15 & MAPK3 & OSBPL6 & PTPDC1 & SATB1 & SVOP & UNC5B \\
\hline ADAP1 & BMPER & CRYM & EXO1 & HAUS8 & KLF2 & MAS1 & OTUD3 & PTPN1 & SCN1A & SYT10 & USP20 \\
\hline ADCY8 & BNIP3L & CUBN & FAM102B & B HMGA2 & KLF7 & MAT2B & PAPPA & PTPRR & SDCCAG8 & SYT12 & USP28 \\
\hline ADM & BRE & CUX2 & FAR1 & HMGCLL1 & KLHL14 & MCCC2 & PDE12 & PUS7 & SDK2 & SYT6 & USP46 \\
\hline AGFG1 & CACNB4 & CX3CL1 & FBXL14 & HS3ST5 & KLHL25 & MED4 & PDK1 & QPCT & SFMBT2 & SYT9 & USP49 \\
\hline AHCYL2 & CAMKK1 & CYLD & FBXL20 & HSD11B1 & KLHL36 & MEIS2 & PDSS2 & RAMP3 & SGMS1 & TAC1 & UST \\
\hline AHI1 & CAPN2 & DAAM1 & FBXO31 & HSPA4L & KLHL7 & MFSD6 & PHACTR3 & RASA1 & SH3BP5 & TBC1D17 & UTP20 \\
\hline AIG1 & CAV1 & DCLK1 & FBXO41 & HTR7 & LASP1 & MICAL2 & PHF14 & RASAL2 & SHC4 & TEAD1 & $\mathrm{VCL}$ \\
\hline AKAP7 & CCDC148 & DDIT4 & FGF13 & IFT122 & LBH & MINK1 & РІК3С3 & RASSF8 & $\mathrm{SIAH} 3$ & TEX264 & VEGFA \\
\hline AKT2 & $\mathrm{CCDC} 53$ & DIAPH1 & FJX1 & IGF2BP2 & LHX2 & MON2 & PLA2G4A & RBAK & SIRT5 & THRB & VWC2L \\
\hline ANK1 & CD200 & DIP2C & FN3KRP & IL1RAP & LIPG & MRM1 & PLCL1 & RCAN2 & SLC22A1 & THSD7A & WASH1 \\
\hline ANKMY2 & CDC14A & DISC1 & FNDC3B & IL1RL2 & LMO2 & MYO9B & PLK2 & REEP1 & SLC25A20 & TM4SF1 & WDR1 \\
\hline ANKRD34C & CDK5 & DLC1 & FRMD3 & INO8OC & LPAR1 & MYRIP & PLXNA2 & RND1 & SLC30A10 & TMEM163 & WNT7A \\
\hline ANKRD6 & CDKN2AIPNL & L DLK1 & FSTL5 & INPP5D & LPL & MYT1L & PMP22 & RNF150 & SLC41A2 & TMEM184B & WSCD2 \\
\hline ANO4 & CHD6 & DOCK8 & GABRG2 & INSC & LRCH1 & NAGA & PNMAL1 & RNF152 & SLC6A17 & TMTC4 & XKR4 \\
\hline AP3S2 & CHN2 & DOK5 & GADD45B & 3 IRF6 & LRFN5 & NAMPT & PNRC1 & RNF180 & SLCO3A1 & TNFAIP1 & XPO4 \\
\hline APBA2 & CHODL & DPF3 & GCLC & ITGA11 & LRRC20 & NCALD & POLE4 & RNGTT & SMARCA2 & TOX3 & ZDHHC14 \\
\hline ARHGAP10 & CHRM2 & DUSP14 & GFPT2 & ITGA6 & LRRC8B & NCOR2 & POLR1A & ROCK2 & SMPD3 & TPK1 & ZMYND8 \\
\hline ARHGEF3 & CLDND1 & DYNC1I1 & GLDN & JAK1 & LTBP1 & NOG & POU4F2 & RPH3A & SNRNP40 & TRIB1 & \\
\hline ARIH1 & CNTN3 & EBF1 & GLRA2 & JAK2 & LUZP1 & NOL10 & PPHLN1 & RPS6KA2 & SORBS2 & TRPC4 & \\
\hline ATP5SL & COBL & EFR3A & GPATCH2 & JAKMIP1 & MAML3 & NR2F1 & PPP2R2B & RPS6KA5 & SPAST & TSC22D1 & \\
\hline $\mathrm{BBC} 3$ & COG3 & EHBP1 & GPR156 & KCNB1 & MAN1A1 & NRF1 & PRKAA1 & RTF1 & SPHKAP & Tाс9 & \\
\hline & & 14 & GPR & & $M A$ & & & & & & \\
\hline
\end{tabular}

Fig. 7 The $W P+B / R X 2+B$ overlapping datasets contain previously validated STAT3 ChIP-sequencing target genes. List of all WP $+B / R X 2+B$ genes (308) that are validated STAT3 ChIP-seq targets (as determined by Zhang, et.al, 2013) in alphabetical order. Highlighted in yellow are genes of special interest

increased exposure to BDNF, as is believed to occur in response to seizures and other brain insults such as traumatic brain injury [53].

The use of primary rat neurons treated with recombinant BDNF allows us to pinpoint the effects of BDNF without the background of additional signaling pathways that may be activated in TLE models. Our study provides a comprehensive list of the changes in the transcriptome that occur in response to a relatively short but continuous exposure to BDNF $(4 \mathrm{~h})$ at a concentration of $0.7 \mathrm{nM}$ that

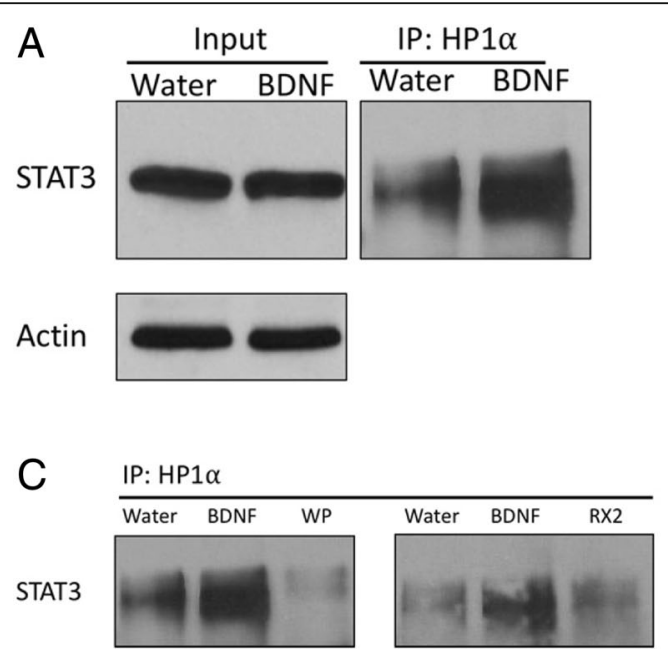

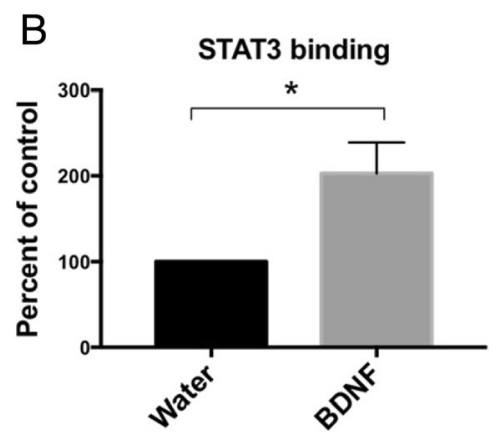

Treatment

Fig. 8 Binding of HP1 to STAT3 is enhanced by BDNF signaling in neurons. a Representative Western Blot image of coimmunoprecipitation assays using whole-cell extracts of 9-DIV primary cortical neurons treated (30 min) with Water or $0.7 \mathrm{nM}$ BDNF. Protein was precipitated with a specific HP1 antibody (Cell Signaling Technologies \#2616) and the elution analyzed by SDS-PAGE. Membrane was immunoblotted with an antiSTAT3 antibody (Cell Signaling Technologies \#4904) to detect co-association of HP1 with STAT3, $(n=4)$. $\mathbf{b}$ Quantitation of STAT3 association with HP1 from dataset in "A". c Representative Western Blot image: Inhibitors of JAK/STAT signaling (WP1066 (WP) and Ruxolitinib 2 (RX2)) reduce HP1a antibody precipitation of STAT3. Data was normalized to ßactin levels which did not change upon BDNF treatment, ${ }^{*}=p<0.05$ 
is relevant to endogenous levels in neurons that activate TrKB receptors and not p75NTR (unpublished data from our laboratory). A collection of the BDNF regulated genes within the list have been previously identified both in treated cultures and in vivo by our laboratory and others. They include Gabra1, the inducible cAMP early repressor (ICER) (which negatively regulates Gabra1) [23], BDNF itself [38], and multiple ion channel genes, as well as genes that code for important markers of neurogenesis and cell proliferation $[54,55]$.

In addition to being consistent with the findings in the literature, our results reveal new BDNF-induced gene targets that are linked to epilepsy. Continuous exposure to BDNF alters the expression of 194 epilepsy-linked genes identified by IPA. The following genes are of particular interest to us because of their marked level of transcriptional alteration and their involvement in epilepsy:

- Dopamine receptor D5 (Drd5)- A D1-type dopamine receptor whose knockdown has been shown to be protective against seizures [56]. In our dataset, the neuronal expression of Drd5 increases nearly 15 -fold in response to BDNF treatment.

- Galinin receptor 1 (Galr1)- Galanin is a neuropeptide in the brain that inhibits glutamate release and galanin agonists delivered to the brain can inhibit seizures [57]. Our dataset reveals a 35fold increase in Galr1 expression, demonstrating the complex medley of both protective and pathogenic changes in genome expression that are invoked by increasing levels of neuronal BDNF.

- Glutamate metabotropic receptor 1 (Grm1)- Grm1 has been associated with the alterations in synaptic plasticity and glutamate disturbances that result in neuronal overexcitation, a hallmark of epilepsy [48, 58]. Grm1 mutations can also cause spinocerebellar ataxia type 44 , a genetic disease that can present with seizures. In our dataset, BDNF treatment led to a 2.45-fold increase in the expression of Grm1.

- $\gamma 2$ subunit of the GABAR (Gabrg2)- the Gabrg2 subunit of GABAR is important for benzodiazepine action and mutations lead to epilepsy [59-62]. In this study, RNA-seq revealed a 2.38 -fold decrease in the expression of Gabrg2 in response to BDNF.

Our new results suggest that sustained levels of BDNF at endogenous concentrations $(0.7 \mathrm{nM})$ can dysregulate a major segment of the epilepsy-associated transcriptome. Recent discovery of the role of BDNF in cancer suggests that understanding how BDNF orchestrates its diverse effects on genome dysregulation will also provide a new window on cancer chemotherapies [63-65]. Surprisingly, beyond its activation of downstream targets like the cAMP regulatory element binding (CREB) protein, whose relationship to BDNF has been rigorously described [66, 67], we still know little about the role of other BDNF controlled transcriptional regulators and their intracellular signaling partners that contribute to disease.

Using the TLE model of epilepsy, we previously showed that during the latent period after pilocarpine-induced SE, there is a marked upregulation in activated CREB and an induction in the expression of the inducible cAMP early repressor (ICER) [23]. We also reported that activated CREB interacts with ICER to downregulate the levels of Gabra1 transcripts leading to a decrease in $\alpha 1$-containing GABARs in hippocampal neurons. In our studies, we discovered that BDNF was linked to the JAK/STAT pathway as 1) STAT3 knockdown blocked ICER induction in response to BDNF, 2) STAT3 was found on the ICER promoter in response to BDNF treatment (as measured by chromatin immunoprecipitation (ChIP), 3) JAK/STAT inhibitors (pyridone 6 and WP1066) blocked ICER induction and Gabra1 downregulation, and 4) in vivo application of WP1066 at the time of pilocarpine-induced SE reduced the frequency of subsequent spontaneous seizures in these animals [32].

Based on these findings, we asked whether the BDNF transcriptome, as identified in our prior studies, could be separated into those where the BDNF response was blocked by exposure to JAK/STAT inhibitors (Fig. 1) and those that were regulated by other pathways. We chose two inhibitors, WP1066 (a JAK2 inhibitor with diverse mechanisms of inhibition [39]), that we showed was active in primary cultures and in vivo, and Ruxolitinib (Ruxo), a high-affinity JAK1/2 inhibitor that blocks JAK activation and is currently used in the treatment of patients with high-risk myelofibrosis. To our surprise, when we compared the transcriptome of cells exposed to BDNF, and to low dose Ruxo plus BDNF (RX1,100 $\mathrm{nM}+\mathrm{B}$ ), we did not see a significant difference between the two datasets. As we show in Fig. 3, this was not due to any issue with the ability of the stock drug to block STAT3 phosphorylation in sister dishes. Phosphorylation-independent STAT3 activity, however, has been described in multiple contexts $[49,68]$ suggesting that JAK/STAT signaling in neurons may act in a non-canonical fashion, at least when activated by prolonged BDNF signaling as studied in our research. A role for unphosphorylated STATs in genome stability and for nuclear JAK2 in the regulation of histone 3 Y41 phosphorylation has been described $[69,70]$ and is the subject of our future studies.

Despite the lack of response of the transcriptome to BDNF in the presence of the high affinity concentration of Ruxo (RX1, $100 \mathrm{nM}$ ), which inhibits STAT3 phosphorylation, WP1066 and Ruxo at $10 \mu \mathrm{M}$ (RX2) 
produced substantial changes in gene expression (Fig. 2a). By comparing the two datasets (WP1066 + B and $\mathrm{RX} 2+\mathrm{B}$ ) we were able to decrease the dimensionality of the BDNF transcriptome into those most relevant by their association with epilepsy. In fact, using enrichment analysis, we discovered an association with epilepsy that is more pronounced than any other neurological disease, due to the large proportion of differentially expressed epilepsy-associated genes present within the WP + B and RX2 + B subset (68\%) (see Additional file 2: Table S2).

Pathway analysis also revealed that JAK/STAT inhibition had a marked effect on reversing the BDNF-induced transcriptional response for genes organized in pathways that control neurogenesis, neuroinflammation, synaptic plasticity, receptor expression, and synaptic transmission. Alterations in these functions exist in the epileptogenic brain, which is known to have altered neurogenesis, mossy-fiber sprouting, inflammation and neuronal pruning leading to increased plasticity, and altered excitation and inhibition at the synapse $[2,3,71]$. They also expand upon the recent findings that JAK/ STAT signaling plays an important role in learning and memory [27], suggesting that impairment in such signaling may be implicated in the cognitive comorbidities of the condition. In the future, it will be important to study these changes in the context of an epileptogenic animal model in vivo where the STAT3 neuronal response can be separated from its nonneuronal counterparts in astrocytes and microglia.

Given that multiple epilepsy-associated genes have been shown to have functional binding sites for STAT3, including BDNF itself (Fig. 7), and considering the substantial relationship between prolonged exposure to BDNF and the ability of JAK/STAT inhibitors to reverse the differential expression of epilepsy associated genes in our studies, we hypothesize that identifying the mechanism that connects BDNF signaling to this novel non-canonical role of JAK/STATs in neurons has the potential to reveal new strategies in the treatment of intractable epilepsy, or its comorbidities, and provide a new window on how neuropharmacology can be used to identify the complex cross-talk between different intracellular signaling pathways in different cell types.

As a first step towards identifying the novel mechanism(s) that drive differential gene expression in response to dysregulated BDNF, we discovered that, contrary to our expectation, BDNF increases the association of HP1 $\alpha$ with STAT3 (see Fig. 8). Perhaps this is not so surprising as HP $1 \alpha$ has also been associated with euchromatin and is particularly important in gene induction $[25,26]$. Future studies will be aimed at learning more about the functional consequences of such protein/protein interactions and their potential role in disease.

\section{Conclusion}

We have employed deep RNA-seq to determine the response of BDNF on the transcriptome of neurons and have employed a neuropharmacological approach to reduce the dimensionality of the datasets to identify BDNF responsive genes whose transcriptional polarity is reversed by two well characterized JAK/STAT inhibitors. Our results show that this subset of genes contains many with previous association to epilepsy in both animal models and human patients. The BDNF-induced JAK/ STAT gene set is highly enriched for genes involved in synaptic neurotransmission, and contains targets from all the major classes of ion channels and neurotransmitter receptors of the brain. In particular, the gene set includes those known to play a role in epileptogenesis through the regulation of synaptic plasticity, neurogenesis, transcriptional regulation, neuroinflammation and proliferation. Some of the genes are known to contain functional STAT recognition sites as verified by ENCODE, while others remain to be interrogated. Pharmacological analysis also revealed that phosphorylation of STAT3 at Tyr705 most likely does not control BDNF-induced JAK/STAT regulation of genome expression in neurons, suggesting that the mechanism is non-canonical. This conclusion is consistent with the additional observation that BDNF regulates the association of HP1 $\alpha$ with STAT3, suggesting that it either regulates heterochromatin structure or plays a novel role in euchromatin. Most importantly, the RNA-seq datasets highlight the importance of the JAK/STAT pathway in neurons and stimulate further discovery in this area based on its potential relevance to brain function and the need to identify new therapeutic strategies for the treatment of intractable neurological disorders.

\section{Methods}

\section{Cell culture and treatments}

Primary neocortical neurons were dissected from neocortex of 3 E18 Sprague-Dawley rat embryos (Charles River Laboratories). Pregnant dams were euthanized by CO 2 according to approved Boston University Institutional animal care and use (IACUC) protocol (AN14327). Embryonic brains were removed and placed in ice-cold $\mathrm{Ca} 2+$ $/ \mathrm{Mg} 2+$ free (CMF) media [Ca 2+ /Mg 2+ free Hanks BSS, $4.2 \mathrm{mM}$ sodium bicarbonate, $1 \mathrm{mM}$ pyruvate, $20 \mathrm{mM}$ HEPES, $3 \mathrm{mg} / \mathrm{mL}$ BSA, pH 7.25-7.3]. Cortices were dissected under a dissection microscope, trypsinized, centrifuged, and triturated in plating media [Neurobasal media (Invitrogen), 10\% fetal bovine serum (Gibco), $100 \mathrm{U} / \mathrm{mL}$ penicillin, $100 \mu \mathrm{g} / \mathrm{mL}$ streptomycin, $200 \mathrm{mM}$ glutamax (Gibco)]. Dissociated neurons were plated on Poly-L-lysine coated 6-well plates $\left(1 \times 10^{6}\right.$ cells/well $)$ and placed in an incubator $\left(37^{\circ} \mathrm{C} / 5 \% \mathrm{CO} 2\right)$ for attachment to plate. $1 \mathrm{~h}$ later, plating media was removed and 
replaced with $2 \mathrm{~mL}$ of defined medium [Neurobasal media (Invitrogen), B27 serum-free supplement (Gibco), $100 \mathrm{U} / \mathrm{mL}$ penicillin, $100 \mu \mathrm{g} / \mathrm{mL}$ streptomycin, $200 \mathrm{mM}$ glutamax (Gibco)]. Neurons were cultured in the incubator for 9 days until use (9 days in vitro [DIV]). Treatments: RNA-seq and P-STAT3 Western Blot- At 9DIV, conditioned media was removed from wells so each well had an equal volume of $1.5 \mathrm{ml}$. Cells were pretreated for 1-h with vehicle dimethyl sulfoxide (DMSO) at 0.1\%, Ruxolitinib (Sellckchem S1378; 100 $\mathrm{nM}$ or 10uM), or WP1066 (EMD Millipore 573,097; $10 \mathrm{uM}$ ). $1.5 \mu \mathrm{L}$ of nuclease-free water (vehicle) or aqueous Brain-derived neurotrophic factor (EMD Millipore GF029; BDNF final concentration $0.7 \mathrm{nM}$ ) was then added to the media (total volume $1.5 \mathrm{ml}$ ) for $4 \mathrm{~h}$ before collection. Due to the small volume of the BDNF or water vehicle addition, effect on media salt concentration was negligible. $N=3$, each $\mathrm{N}$ represents cells collected from one pregnant dam. Enough primary cells were collected from each $\mathrm{N}$ sufficient for 1 biological replicate of each treatment. HP1 $\alpha$ Pulldown: At 9-DIV cells were pretreated for 1-h with dimethyl sulfoxide (DMSO) at 0.1\%, Ruxolitinib (Sellckchem S1378; 10uM), or WP1066 (EMD Millipore 573,097; 10uM). Nuclease-free water vehicle or Brain-derived neurotrophic factor was then added (EMD Millipore GF029; $0.7 \mathrm{nM}$ ) for $30 \mathrm{~min}$ before collection, $N=4$.

\section{RNA extraction and library preparation}

At the end of the 4-h treatment period, cells were collected and RNA extracted using the Qiagen RNeasy Micro Kit with DNAase treatment (Cat. 74,004). RNA was run in the Agilent Bioanalyzer to determine RNA integrity number (RIN). RIN of all samples was $\geq 9.0$. mRNA was selected by using the NEBNext ${ }^{\circ}$ Poly(A) mRNA Magnetic Isolation Module (E7490S) before using the NEBNext ${ }^{\circ}$ Ultra $^{\text {tw }}$ Directional RNA Library Prep Kit for Illumina ${ }^{\circ}$ (E7420S) with Agencourt AMPure XP Clean up beads (A63881) to make RNA into strand specific cDNA libraries with multiplexing barcodes from the NEBNext ${ }^{\circ}$ Multiplex Oligos for Illumina ${ }^{\circ}$ (Index Primers Set 1) kit (E7335S).

\section{Illumina sequencing}

Sequencing was performed at the Boston University Microarray Core and University of Chicago Genome Center. Fragmentation and concentration were analyzed on the Agilent Bioanalyzer and Fragment analyzer prior to sample pooling. Runs were either sequenced at $75 \mathrm{bp}$ single-end reads on the Illumina NextSeq sequencer to a depth of 100-120 million reads per sample or at $50 \mathrm{bp}$ single-end reads on the Illumina HiSeq sequencer to a depth of 90-100 reads per sample. All samples were multiplexed and pooled using barcodes to separate biological replicates.

\section{RNA-seq bioinformatics}

Data analysis was performed using Strand NGS software, Version 3.2, Build 237,248.C Strand Life Sciences, Bangalore, India. Proprietary Strand NGS algorithms were used to conduct read alignment to the rat genome build rn6 RefSeq Genes (2016.05.11). Reads were filtered based on the following parameters: Max number of novel splices: 1, Min alignment score: 90, Number of gaps allowed: 5, number of matches to be output for each read: 1 , exclude reads with alignment length less than: 25, ignore reads with matches more than: 5, Trim 3 ' end with average base quality less than: 10. RNA quantification was performed by the Strand NGS software, which counts the total number of reads that map to each gene and exon in the genome, and is reported as raw counts. Normalization of the raw counts was achieved using the DESeq method, which accounts for difference in the total number of reads between samples and $\log$ transforms the data [72]. $\mathrm{R}$ version 3.1.2 was used with DEseq2 version 1.6.1 to determine differential expression FDR $=0.05$, Wald test type. The list of significant genes was then used in subsequent analyses. Disease involvement data was analyzed through the use of IPA with proprietary statistical algorithms (QIAGEN Inc., https:/www.qiagenbioinformatics.com /products/ ingenuitypathway-analysis). Cytoscape 3.5.1 software was used with GeneMANIA for functional network generation with [42, 43]. EnrichR was used for GO-term analysis and KEGG pathway analysis [40, 41].

\section{Real-time quantitative reverse transcriptase PCR (qRT-PCR)}

Primary neurons were prepared, treated, and RNA extracted, as described above for RNA-seq. The Applied Biosystems 1-step RNA to Ct (cat. 4,392,938) kit was used and protocol was followed as directed: $50 \mathrm{ng}$ of RNA template, $10 \mu \mathrm{L}$ of $2 \mathrm{x}$ mastermix, $0.5 \mu \mathrm{L}$ of each 40x primer/probe kit (Ppia and the gene of interest), $0.5 \mu \mathrm{L}$ of the enzyme mix, and nuclease free water was added to each $20 \mu \mathrm{L}$ reaction. Each reaction was performed with 2 technical replicates in a 384-well plate. All taqman primer/probe kits were ordered from Thermo Fisher Scientific. Assay ID: Ppia (housekeeping): Rn00690933_m1 VIC-MGB; Galr1: Rn04932425_m1 FAM-MGB; Drd5: Rn00562768_s1 FAM-MGB; Jak2: Rn00676341_m1 FAM-MGB; Gabrg2: Rn01464079_m1 FAM-MGB; Grm1: Rn00566625_m1 FAM-MGB; Icer: Rn00569145_m1 FAM-MGB; Ccnd1: Rn00432359_m1 FAM-MGB; Socs3: Rn00585674_s1 FAM-MGB; Mcl1: Rn00821024_g1 FAM-MGB; Cxcr4: Rn00573522_s1.

The Applied Biosystems 7900 HT Real-Time PCR system was used to run with the following cycling parameters: $48^{\circ} \mathrm{C} 15 \mathrm{~min}$. Hold (Reverse Transcription), $95^{\circ} \mathrm{C}$ $10 \mathrm{~min}$. Hold, 40 cycles: $95^{\circ} \mathrm{C} 15 \mathrm{~s}, 60^{\circ} \mathrm{C} 1 \mathrm{~min}$. After 
run completion, the $\Delta \Delta C T$ method was used to calculate the relative values of the transcripts.

\section{Western blot and immunoprecipitation}

Primary cortical cultures used for Western Blot were prepared and treated with drugs the same as described for RNA-seq. After the 4-h period of BDNF treatment, cells were washed once with ice-cold PBS solution (PBS + EDTA, 1x PhosStop (Roche) and 1x Protease Inhibitor cocktail (Roche cOmplete protease inhibitor)) and centrifuged in $1.5 \mathrm{~mL}$ tubes at 5000RPM for $4 \mathrm{~min}$ at $4{ }^{\circ} \mathrm{C}$. PBS was removed and cell pellet was resuspended in 1x RIPA buffer (with 1x Protease and Phosphatase inhibitors). Lysates were incubated on a rotator at $4{ }^{\circ} \mathrm{C}$ for $15 \mathrm{~min}$, then centrifuged at 13000 RPM for $10 \mathrm{~min}$. Supernatant was transferred to a fresh tube and aliquoted for Western Blot or Immunoprecipitation. For non-immunoprecipitated samples, $35 \mu \mathrm{g}$ of sample was diluted to $10 \mu \mathrm{L}$ in RIPA buffer and $10 \mu \mathrm{L}$ of $2 \mathrm{x}$ SDS Tris-Glycine loading buffer (Invitrogen LC2676) with $50 \mathrm{mM}$ DTT. For immunoprecipitation, Active Motif Universal Magnetic Co-IP kit (Cat. \#54002) was used. Three hundred microgram of protein was incubated overnight at $4{ }^{\circ} \mathrm{C}$ with $15 \mu \mathrm{L} \mathrm{HP} 1 \alpha$ antibody (Cell Signaling Technology \#2616). Samples were then incubated in magnetic bead solution from the kit for $1 \mathrm{~h}$ before elution into 20uL SDS Tris-Glycine loading buffer (Invitrogen LC2676) with $50 \mathrm{mM}$ DTT. All samples were boiled at $95^{\circ} \mathrm{C}$ for $5 \mathrm{~min}$, centrifuged and loaded into a Novex 10\% Wedgewell gel (Invitrogen XP00100BOX). The gel was run at $220 \mathrm{~V}$ for $40 \mathrm{~min}$ and wet transfer was performed at $33 \mathrm{~V}$ for $2 \mathrm{~h}$ to a nitrocellulose membrane. Membrane was quickly washed in TBST then blocked in $5 \%$ milk in TBST for $1 \mathrm{~h}$ at room temperature. Three $5 \mathrm{~min}$ washes in TBST were performed. Membrane was incubated overnight at $4{ }^{\circ} \mathrm{C}$ in primary antibody then washed $3 \times 10$ minutes in TBST. HRP-conjugated secondary was added for $1 \mathrm{~h}$ at room temperature, then 3 washes in $1 \%$ milk were performed prior to imaging the blot with ECL (BioRad Clarity \#1705060). Membrane was stripped using the GM Biosciences One Minute Advance Stripping buffer \#GM6031. Antibodies were used as follows: 1:1000 pSTAT3 (CST \#9131S) in 5\% BSA, 1:5000 anti-rabbit HRP-conjugated secondary antibody (EMD Millipore AP132P) in 1\% milk in TBST. 1:2000 total STAT3 (CST \#4904S) in 5\% milk in TBST. 1:6000 $\beta$-actin (Sigma A5441) in 1\% milk in TBST, 1:2500 Anti-mouse HRP-conjugated secondary antibody (Vector Labs PI2000) in 1\% milk in TBST.

\section{Additional files}

Additional file 1: Table S1. Genes of interest in the dataset and their relationship to epilepsy. Several genes of particular interest to the field of epilepsy are listed with the degree of FC from DMSO+Water vs. DMSO+BDNF and the FC of DMSO+BDNF vs. WP1066 + BDNF. Many have not been associated with the JAK/STAT pathway or BDNF regulation. The name of the gene, the related function, and a reference to support the potential relationship with epilepsy is listed. (PDF $196 \mathrm{~kb}$ )

Additional file 2: Table S2. Top Neurological disease relationships determined by IPA. (A) Top 10 significantly enriched neurological diseases in the BDNF transcriptome with their p-value (IPA). (B) Top 10 significantly enriched neurological diseases in the WP/RX2 vs. BDNF set of differentially expressed genes listed with their p-value from IPA. (PDF $180 \mathrm{~kb}$ )

Additional file 3: Figure S1. Volcano Plot of BDNF regulated genes whose response is reversed by $W P+B / R X 2+B$. Representation of degree of fold change and significance used to narrow down the list of top genes to include in the Fig. 3 network. Teal-genes upregulated by both WP $+B$ and RX2 + B; Blue: genes upregulated by WP + B only; Red: genes downregulated by both WP $+B$ and $\mathrm{R} X 2+\mathrm{B}$; Pink: genes downregulated only by WP + B; Yellow: genes that did not meet cutoffs of $>2$ FC, $p<$ 1e-10. Teal and Red gene list used for Fig. 3 network. Maximum $-\log 10 p$ value detected was 45, $p$ values more significant than 45 are represented as $-\log 10$ of 45. (PDF $103 \mathrm{~kb}$ )

Additional file 4: Figure S2. Enrichment Analysis of BDNF regulated genes whose expression is reversed exclusively by 10uM Ruxo. Enrichment analysis was performed on the set of 417 DEGs between $\mathrm{RX} 2+\mathrm{B}$ vs. $\mathrm{V}+\mathrm{B}$ that were not overlapping with WP + B. (A) KEGG pathway analysis as generated in EnrichR ranked and colored by $P$ value. (B) Top gene clusters involved in the KEGG canonical pathways from A. (C-E) Neurological diseases significantly associated with the RX2 exclusive gene set for (C) Epilepsy, (D) Huntington's disease, (E)

Neurodegeneration. (PDF 279 kb)

Additional file 5: List of significant genes and FC values for all relevant comparisons. Comprehensive list of genes that were significantly different when comparing various treatments (PDF $493 \mathrm{~kb}$ )

\section{Abbreviations}

AMPA: a-amino-3-hydroxy-5-methyl-4-isoxazolepropionic acid; BDNF: Brainderived neurotrophic factor; ChIP: Chromatin Immunoprecipitation; DEG: Differentially expressed genes; Drd5: Dopamine receptor D5; ERK: Extracellular-signal-regulated kinase; GABA: Gamma-Aminobutyric Acid; Gabra1: Gaba A receptor alpha 1 subunit; Gabrg2: Gaba A receptor gamma 2 subunit; Galr1: Galinin receptor 1; GO: Gene ontology; GPCR: G-proteincoupled receptor; Grm1: Glutamate metabatropic receptor 1;

HP1a: Heterochromatin Protein 1 alpha; IACUC: Institutional animal care and use; Icer: Inducible cyclic-AMP early repressor; IPA: Ingenuity pathway analysis; JAK/STAT: Janus kinases (JAK); JNK: c-Jun N-terminal kinase; LTD: Long-term depression; LTP: Long-term potentiation; MAPK: Mitogenactivated protein kinase; mRNA: Messenger ribonucleic acid; NF-KB: Nuclear factor kappa-light-chain-enhancer of activated B cells; NGFR: Nerve growth factor receptor; P75NTR: p75 Neurotrophin receptor; PI3K: Phosphoinositide 3-kinase; PILO: Pilocarpine; PLCY: Phospholipase C gamma; qRT-

PCR: Quantitative real-time polymerase chain reaction; RUXO: Ruxolitinib; SE: Status Epilepticus; STAT: Signal Transducer and Activator of Transcription; TBI: Traumatic brain injury; TLE: Temporal lobe epilepsy; TrkB: Tropomyosin receptor kinase $\mathrm{B}$

\section{Acknowledgements}

We would like to acknowledge the work of previous members of the Russek laboratory that have provided the creative environment needed to pursue the mechanism of this novel signaling pathway in the brain, Drs. Rebecca Benham and Kristen Hokenson, as well as our colleagues in the Department of Pharmacology and the Graduate Program for Neuroscience. We also thank the members of the Brooks-Kayal laboratory for providing a wonderful collegial environment for translational research efforts.

\section{Authors' contributions}

$\mathrm{KH}$ performed the experiments, analysis, and wrote the manuscript with input from all authors. MC assisted with study design and data analysis. ABK assisted with study design and results interpretation. SR oversaw study design, experimental work, data analysis and read, edited and wrote the final manuscript. All authors read and approved the final manuscript. 


\section{Funding}

Funding was generously provided by the following grants:

NIGMS T32GM008541; stipend support and partial graduate training for $\mathrm{K}$. Hixson.

NINDS R01NS051710; supported data collection, design, analysis, interpretation, and writing. PIs A.R. Brooks-Kayal and S.J. Russek. NINDS R21 NS083057; enabled the initial discovery of JAKSTAT inhibitor selection and use in vivo. PIs A.R. Brooks-Kayal and S.J. Russek. CURE Epilepsy Multidisciplinary Award; funding brought together research laboratories and helped build hypotheses for R01 and R21 applications. PIs A.R. Brooks-Kayal and S.J. Russek.

\section{Availability of data and materials}

All data generated and analyzed during our study which support the conclusions of the article are included in the Additional files. All aligned sequencing files (.bam) are publicly available in the NCBI SRA database (SRA accession: PRJNA554446) at this link:

http://www.ncbi.nlm.nih.gov/bioproject/554446

\section{Ethics approval and consent to participate}

Rats were sacrificed in accordance with the Boston University practice for laboratory animal procedures. The protocol (AN14327) was approved by the Boston University Institutional Animal Care and Use committee (IACUC).

\section{Consent for publication}

Not Applicable.

\section{Competing interests}

There are no conflicts of interest for any of the authors on this manuscript.

\section{Author details}

'Laboratory of Translational Epilepsy, Department of Pharmacology \& Experimental Therapeutics, Boston University School of Medicine (BUSM), Boston, USA. ${ }^{2}$ Graduate Program for Neuroscience (GPN), Boston University (BU), Boston, USA. ${ }^{3}$ Department of Pediatric Neurology, University of Colorado Anschutz Medical Campus, Aurora, USA. ${ }^{4}$ Department of Biology, Boston University (BU), Boston, USA.

\section{Received: 23 January 2019 Accepted: 15 August 2019}

\section{Published online: 28 August 2019}

\section{References}

1. Danzer SC. Contributions of adult-generated granule cells to hippocampal pathology in temporal lobe epilepsy: a neuronal bestiary. Brain Plast. 2018 3(2):169-81 Luikart BW, editor.

2. Sutula T, Cascino G, Cavazos J, Parada I, Ramirez L. Mossy fiber synaptic reorganization in the epileptic human temporal lobe. Ann Neurol. 1989; 26(3):321-30.

3. Mathern GW, Babb TL, Leite JP, Pretorius K, Yeoman KM, Kuhlman PA. The pathogenic and progressive features of chronic human hippocampal epilepsy. Epilepsy Res. 1996;26(1):151-61.

4. Kullmann DM, Asztely F, Walker MC. The role of mammalian ionotropic receptors in synaptic plasticity: LTP, LTD and epilepsy. Cell Mol Life Sci. 2000:57(11):1551-61.

5. Brooks-Kayal AR, Shumate MD, Jin H, Rikhter TY, Coulter DA. Selective changes in single cell GABA a receptor subunit expression and function in temporal lobe epilepsy. Nat Med. 1998;4(10):1166-72.

6. Friedman LK, Pellegrini-Giampietro DE, Sperber EF, Bennett MV, Moshé SL, Zukin RS. Kainate-induced status epilepticus alters glutamate and GABAA receptor gene expression in adult rat hippocampus: an in situ hybridization study. J Neurosci. 1994;14(5 Pt 1):2697-707.

7. Cossart R, Dinocourt C, Hirsch JC, Merchan-Perez A, De Felipe J, Ben-Ari Y, et al. Dendritic but not somatic GABAergic inhibition is decreased in experimental epilepsy. Nat Neurosci. 2001;4(1):52-62.

8. Murray KD, Isackson PJ, Eskin TA, King MA, Montesinos SP, Abraham LA, et al. Altered mRNA expression for brain-derived neurotrophic factor and type II calcium/calmodulin-dependent protein kinase in the hippocampus of patients with intractable temporal lobe epilepsy. J Comp Neurol. 2000; 418(4):411-22.

9. Takahashi M, Hayashi S, Kakita A, Wakabayashi K, Fukuda M, Kameyama S, et al. Patients with temporal lobe epilepsy show an increase in brain-derived neurotrophic factor protein and its correlation with neuropeptide Y. Brain Res. 1999:818(2):579-82.

10. Kokaia M, Ernfors P, Kokaia Z, Elmér E, Jaenisch R, Lindvall O. Suppressed Epileptogenesis in BDNF mutant mice. Exp Neurol. 1995;133(2):215-24.

11. He X-P, Kotloski R, Nef S, Luikart BW, Parada LF, McNamara JO. Conditional deletion of TrkB but not BDNF prevents Epileptogenesis in the kindling model. Neuron. 2004;43(1):31-42.

12. Heinrich $C$, Lähteinen $S$, Suzuki F, Anne-Marie L, Huber S, Häussler U, et al. Increase in BDNF-mediated TrkB signaling promotes epileptogenesis in a mouse model of mesial temporal lobe epilepsy. Neurobiol Dis. 2011;42(1):35-47.

13. Riffault B, Kourdougli N, Dumon C, Ferrand N, Buhler E, Schaller F, et al. Probrain-derived neurotrophic factor (proBDNF)-mediated p75NTR activation promotes depolarizing actions of GABA and increases susceptibility to epileptic seizures. Cereb Cortex. 2018;28(2):510-27.

14. VonDran MW, LaFrancois J, Padow VA, Friedman WJ, Scharfman HE, Milner TA, et al. p75 NTR, but not proNGF, is upregulated following status epilepticus in mice. ASN Neuro. 2014;6(5):175909141455218.

15. Thomas AX, Cruz Del Angel Y, Gonzalez MI, Carrel AJ, Carlsen J, Lam PM, et al. Rapid increases in proBDNF after pilocarpine-induced status epilepticus in mice are associated with reduced proBDNF cleavage machinery. eNeuro. 2016:3(1). https://www.eneuro.org/content/3/1

16. Kaplan DR, Miller FD. Signal transduction by the neutrophin receptors. Curr Opin Cell Biol. 1997;9(2):213-21.

17. Binder DK, Scharfman HE. CHAPTER 3 the role of BDNF in epilepsy and other diseases of the mature nervous system. Recent Adv Epilepsy Res. 2004.

18. Yamada K, Nabeshima T. Interaction of BDNF/TrkB signaling with NMDA receptor in learning and memory. Drug News Perspect. 2004;17(7):435-8.

19. Xu B, Gottschalk W, Chow A, Wilson Rl, Schnell E, Zang K, et al. The role of brain-derived neurotrophic factor receptors in the mature hippocampus: modulation of long-term potentiation through a presynaptic mechanism involving TrkB. J Neurosci. 2000;20(18):6888-97.

20. Muller D, Djebbara-Hannas $Z$, Jourdain P, Vutskits L, Durbec $P$, Rougon G, et al. Brain-derived neurotrophic factor restores long-term potentiation in polysialic acid-neural cell adhesion molecule-deficient hippocampus. Proc Natl Acad Sci U S A. 2000;97(8):4315-20.

21. Minichiello L, Calella AM, Medina DL, Bonhoeffer T, Klein R, Korte M. Mechanism of TrkB-mediated hippocampal long-term potentiation. Neuron. 2002:36(1):121-37.

22. Rösch H, Schweigreiter R, Bonhoeffer T, Barde Y-A, Korte M. The neurotrophin receptor p75NTR modulates long-term depression and regulates the expression of AMPA receptor subunits in the hippocampus. Proc Natl Acad Sci U S A. 2005;102(20):7362-7.

23. Lund IV, Hu Y, Raol YH, Benham RS, Faris R, Russek SJ, et al. BDNF selectively regulates GABAA receptor transcription by activation of the JAK/STAT pathway. Sci Signal. 2008;1(41):ra9.

24. Li WX. Canonical and non-canonical JAK-STAT signaling. Trends Cell Biol. 2008;18(11):545-51.

25. Piacentini L, Fanti L, Berloco M, Perrini B, Pimpinelli S. Heterochromatin protein $1(\mathrm{HP} 1)$ is associated with induced gene expression in Drosophila euchromatin. J Cell Biol. 2003;161(4):707-14

26. Kwon SH, Workman JL. The changing faces of HP1: from heterochromatin formation and gene silencing to euchromatic gene expression: HP1 acts as a positive regulator of transcription. Bioessays. 2011:33(4):280-9.

27. Nicolas CS, Peineau S, Amici M, Csaba Z, Fafouri A, Javalet C, et al. The JAK STAT pathway is involved in synaptic plasticity. Neuron. 2012;73(2):374-90.

28. Lavoie AM, Tingey JJ, Harrison NL, Pritchett DB, Twyman RE. Activation and deactivation rates of recombinant GABA(a) receptor channels are dependent on alpha-subunit isoform. Biophys J. 1997;73(5):2518-26.

29. Petryshen TL, Middleton FA, Tahl AR, Rockwell GN, Purcell S, Aldinger KA, et al. Genetic investigation of chromosome $5 q$ GABAA receptor subunit genes in schizophrenia. Mol Psychiatry. 2005:10(12):1074-88.

30. Raud S, Sütt S, Luuk H, Plaas M, Innos J, Kõks S, et al. Relation between increased anxiety and reduced expression of alpha1 and alpha2 subunits of GABAA receptors in Wfs1-deficient mice. Neurosci Lett. 2009:460(2):138-42.

31. Bossers K, Wirz KTS, Meerhoff GF, Essing AHW, van Dongen JW, Houba P, et al. Concerted changes in transcripts in the prefrontal cortex precede neuropathology in Alzheimer's disease. Brain. 2010;133(12):3699-723.

32. Grabenstatter HL, Del Angel YC, Carlsen J, Wempe MF, White AM, Cogswell $M$, et al. The effect of STAT3 inhibition on status epilepticus and subsequent spontaneous seizures in the pilocarpine model of acquired epilepsy. Neurobiol Dis. 2014;62:73-85. 
33. Zhou T, Georgeon S, Moser R, Moore DJ, Caflisch A, Hantschel O. Specificity and mechanism-of-action of the JAK2 tyrosine kinase inhibitors ruxolitinib and SAR302503 (TG101348). Leukemia. 2014;28(2):404-7.

34. QIAGEN Inc. Ingenuity Pathway Analysis [Internet]. Available from: https:// www.qiagenbioinformatics.com/products/ingenuitypathway-analysis). Accessed Apr 2018.

35. Claes L, Del-Favero J, Ceulemans B, Lagae L, Van Broeckhoven C, De Jonghe $P$. De novo mutations in the Sodium-Channel gene SCN1A cause severe myoclonic epilepsy of infancy. Am J Hum Genet. 2001;68(6):1327-32.

36. Biervert C, Schroeder BC, Kubisch C, Berkovic SF, Propping P, Jentsch TJ, et al. A potassium channel mutation in neonatal human epilepsy. Science. 1998;279(5349):403-6.

37. Jouvenceau A, Eunson LH, Spauschus A, Ramesh V, Zuberi SM, Kullmann DM, et al. Human epilepsy associated with dysfunction of the brain P/Qtype calcium channel. Lancet. 2001;358(9284):801-7.

38. Tuvikene J, Pruunsild P, Orav E, Esvald E-E, Timmusk T. AP-1 transcription factors mediate BDNF-positive feedback loop in cortical neurons. J Neurosci. 2016;36(4):1290-305

39. Verstovsek S, Manshouri T, Quintás-Cardama A, Harris D, Cortes J, Giles FJ, et al. WP1066, a novel JAK2 inhibitor, suppresses proliferation and induces apoptosis in erythroid human cells carrying the JAK2 V617F mutation. Clin Cancer Res. 2008;14(3):788-96.

40. Kuleshov MV, Jones MR, Rouillard AD, Fernandez NF, Duan Q, Wang Z, et al. Enrichr: a comprehensive gene set enrichment analysis web server 2016 update. Nucleic Acids Res. 2016;44(W1):W90-7.

41. Chen EY, Tan CM, Kou Y, Duan Q, Wang Z, Meirelles G, et al. Enrichr: interactive and collaborative HTML5 gene list enrichment analysis tool. BMC Bioinformatics. 2013;14(1):128.

42. Shannon P, Markiel A, Ozier O, Baliga NS, Wang JT, Ramage D, et al. Cytoscape: a software environment for integrated models of biomolecular interaction networks. Genome Res. 2003;13(11):2498-504.

43. Warde-Farley D, Donaldson SL, Comes O, Zuberi K, Badrawi R, Chao P, et al. The GeneMANIA prediction server: biological network integration for gene prioritization and predicting gene function. Nucleic Acids Res. 2010; 38(suppl_2):W214-20.

44. Roberts DS, Hu Y, Lund IV, Brooks-Kayal AR, Russek SJ. Brain-derived neurotrophic factor (BDNF)-induced synthesis of early growth response factor 3 (Egr3) controls the levels of type a GABA Receptora4 subunits in hippocampal neurons. J Biol Chem. 2006;281(40):29431-5.

45. Zhang J-X, Zhang J, Yan W, Wang Y-Y, Han L, Yue X, et al. Unique genomewide map of TCF4 and STAT3 targets using ChIP-seq reveals their association with new molecular subtypes of glioblastoma. Neuro-Oncology. 2013;15(3):279-89.

46. Binder DK, Croll SD, Gall CM, Scharfman HE. BDNF and epilepsy: too much of a good thing? Trends Neurosci. 2001;24(1):47-53.

47. Escayg A, De Waard M, Lee DD, Bichet D, Wolf P, Mayer T, et al. Coding and noncoding variation of the human Calcium-Channel $\beta 4$-subunit gene CACNB4 in patients with idiopathic generalized epilepsy and episodic Ataxia. Am J Hum Genet. 2000;66(5):1531-9.

48. Watson LM, Bamber E, Schnekenberg RP, Williams J, Bettencourt C, Lickiss J, et al. Dominant mutations in GRM1 cause spinocerebellar Ataxia type 44. Am J Hum Genet. 2017;101(3):451-8.

49. Shi S, Larson K, Guo D, Lim SJ, Dutta P, Yan S-J, et al. Drosophila STAT is required for directly maintaining HP1 localization and heterochromatin stability. Nat Cell Biol. 2008;10(4):489-96.

50. McNamara JO, Scharfman HE. Temporal lobe epilepsy and the BDNF receptor, TrkB. In: Jasper's Basic Mechanisms of the Epilepsies; 2012.

51. Lipovich L, Dachet F, Cai J, Bagla S, Balan K, Jia H, et al. Activity-dependent human brain coding/noncoding gene regulatory networks. Genetics. 2012; 192(3):1133-48.

52. Brooks-Kayal AR, Russek SJ. Regulation of GABAA receptor gene expression and epilepsy. Epilepsia. 2010:51:51-1.

53. Raible DJ, Frey LC, Cruz Del Angel Y, Russek SJ, Brooks-Kayal AR. GABA(a) receptor regulation after experimental traumatic brain injury. J Neurotrauma. 2012;29(16):2548-54.

54. Boles NC, Hirsch SE, Le S, Corneo B, Najm F, Minotti AP, et al. NPTX1 regulates neural lineage specification from human pluripotent stem cells. Cell Rep. 2014;6(4):724-36.

55. Qiao Z, Kito F, Takai Y, Oyama R, Kondo T. Secretomics identifies follistatin as a predictive biomarker for response to treatment with tyrosine kinase inhibitors in synovial sarcoma. J Electrophor. 2017;61(1):1-7.
56. O'Sullivan GJ, Dunleavy M, Hakansson K, Clementi M, Kinsella A, Croke DT, et al. Dopamine D1 vs D5 receptor-dependent induction of seizures in relation to DARPP-32, ERK1/2 and GluR1-AMPA signalling. Neuropharmacology. 2008:54(7):1051-61.

57. Mazarati AM. Galanin and galanin receptors in epilepsy. Neuropeptides. 2004:38(6):331-43.

58. Ichise T, Kano M, Hashimoto K, Yanagihara D, Nakao K, Shigemoto R, et al. mGluR1 in cerebellar Purkinje cells essential for long-term depression, synapse elimination, and motor coordination. Science. 2000;288(5472):18325 .

59. Audenaert D, Schwartz E, Claeys KG, Claes L, Deprez L, Suls A, et al. A novel GABRG2 mutation associated with febrile seizures. Neurology. 2006;67(4): 687-90

60. Chou I-C, Lee C-C, Tsai C-H, Tsai Y, Wan L, Hsu Y-A, et al. Association of GABRG2 polymorphisms with idiopathic generalized epilepsy. Pediatr Neurol. 2007;36(1):40-4.

61. Kananura C, Haug K, Sander T, Runge U, Gu W, Hallmann K, et al. A splicesite mutation in GABRG2 associated with childhood absence epilepsy and febrile convulsions. Arch Neurol. 2002;59(7):1137.

62. Bianchi MT, Song L, Zhang H, Macdonald RL. Two different mechanisms of disinhibition produced by GABAA receptor mutations linked to epilepsy in humans. J Neurosci. 2002;22(13):5321-7.

63. Radin DP, Patel PBDNF. An oncogene or tumor suppressor? Anticancer Res. 2017:37(8):3983-90.

64. Yin B, Ma ZY, Zhou ZW, Gao WC, Du ZG, Zhao ZH, et al. The TrkB+ cancer stem cells contribute to post-chemotherapy recurrence of triple-negative breast cancers in an orthotopic mouse model. Oncogene. 2015;34(6):76170 .

65. Zhang S, Hui L, Li C, Gao J, Cui Z, Qiu X. More expression of BDNF associates with lung squamous cell carcinoma and is critical to the proliferation and invasion of lung cancer cells. BMC Cancer. 2016;16(1):171.

66. Finkbeiner S, Tavazoie SF, Maloratsky A, Jacobs KM, Harris KM, Greenberg ME. CREB: a major mediator of neuronal Neurotrophin responses. Neuron. 1997;19(5):1031-47.

67. Tao X, Finkbeiner S, Arnold DB, Shaywitz AJ, Greenberg ME. Ca2+ influx regulates BDNF transcription by a CREB family transcription factordependent mechanism. Neuron. 1998;20(4):709-26.

68. Yang J, Liao X, Agarwal MK, Barnes L, Auron PE, Stark GR. Unphosphorylated STAT3 accumulates in response to IL-6 and activates transcription by binding to NFkappaB. Genes Dev. 2007;21(11):1396-408.

69. Dawson MA, Bannister AJ, Göttgens B, Foster SD, Bartke T, Green AR, et al. JAK2 phosphorylates histone H3Y41 and excludes HP1 a from chromatin. Nature. 2009;461(7265):819-22.

70. Zouein FA, Duhé RJ, Booz GW. JAKs go nuclear: emerging role of nuclear JAK1 and JAK2 in gene expression and cell growth. Growth Factors. 2011 Dec;29(6):245-52.

71. Vezzani A, French J, Bartfai T, Baram TZ. The role of inflammation in epilepsy. Nat Rev Neurol. 2011;7(1):31-40.

72. Anders S, Huber W. Differential expression analysis for sequence count data. Genome Biol. 2010;11(10):R106.

\section{Publisher's Note}

Springer Nature remains neutral with regard to jurisdictional claims in published maps and institutional affiliations.

Ready to submit your research? Choose BMC and benefit from:

- fast, convenient online submission

- thorough peer review by experienced researchers in your field

- rapid publication on acceptance

- support for research data, including large and complex data types

- gold Open Access which fosters wider collaboration and increased citations

- maximum visibility for your research: over $100 \mathrm{M}$ website views per year

At $\mathrm{BMC}$, research is always in progress.

Learn more biomedcentral.com/submission 